\title{
Monocyte-Derived Macrophages Contribute to Spontaneous Long-Term Functional Recovery after Stroke in Mice
}

\author{
Somsak Wattananit, ${ }^{1}$-Daniel Tornero, ${ }^{1}$ Nadine Graubardt, ${ }^{3}$-Tamar Memanishvili, ${ }^{1,4}$ Emanuela Monni, \\ Jemal Tatarishvili, ${ }^{1}$ Giedre Miskinyte, ${ }^{1}$ Ruimin Ge, ${ }^{1}$ Henrik Ahlenius, ${ }^{2}$ Olle Lindvall, ${ }^{1}$ Michal Schwartz, ${ }^{3}$ \\ and Zaal Kokaia ${ }^{1}$ \\ ${ }^{1}$ Laboratory of Stem Cells and Restorative Neurology and ${ }^{2}$ Stem Cells, Aging, and Neurodegeneration Group, Lund Stem Cell Center, University Hospital, \\ 221 84, Lund, Sweden, ${ }^{3}$ Department of Neurobiology, Weizmann Institute of Science, 7610001, Rehovot, Israel, and ${ }^{4}$ I. Javakhishvili Tbilisi State University, \\ 0179, Tbilisi, Georgia
}

Stroke is a leading cause of disability and currently lacks effective therapy enabling long-term functional recovery. Ischemic brain injury causes local inflammation, which involves both activated resident microglia and infiltrating immune cells, including monocytes. Monocyte-derived macrophages (MDMs) exhibit a high degree of functional plasticity. Here, we determined the role of MDMs in longterm spontaneous functional recovery after middle cerebral artery occlusion in mice. Analyses by flow cytometry and immunocytochemistry revealed that monocytes home to the stroke-injured hemisphere., and that infiltration peaks $3 \mathrm{~d}$ after stroke. At day 7, half of the infiltrating MDMs exhibited a bias toward a proinflammatory phenotype and the other half toward an anti-inflammatory phenotype, but during the subsequent 2 weeks, MDMs with an anti-inflammatory phenotype dominated. Blocking monocyte recruitment using the anti-CCR2 antibody MC-21 during the first week after stroke abolished long-term behavioral recovery, as determined in corridor and staircase tests, and drastically decreased tissue expression of anti-inflammatory genes, including TGF $\beta$, CD163, and Ym1. Our results show that spontaneously recruited monocytes to the injured brain early after the insult contribute to long-term functional recovery after stroke.

Key words: macrophage; microglia; monocyte; neuroinflammation; stroke

\section{Significance Statement}

For decades, any involvement of circulating immune cells in CNS repair was completely denied. Only over the past few years has involvement of monocyte-derived macrophages (MDMs) in CNS repair received appreciation. We show here, for the first time, that MDMs recruited to the injured brain early after ischemic stroke contribute to long-term spontaneous functional recovery through inflammation-resolving activity. Our data raise the possibility that inadequate recruitment of MDMs to the brain after stroke underlies the incomplete functional recovery seen in patients and that boosting homing of MDMs with an antiinflammatory bias to the injured brain tissue may be a new therapeutic approach to promote long-term improvement after stroke.

\section{Introduction}

Ischemic stroke is followed by local immune responses that encompass microglia and monocyte-derived macrophages (MDMs) infil-

Received Dec. 1, 2015; revised Feb. 14, 2016; accepted March 1, 2016.

Author contributions: S.W., 0.L., M.S., and Z.K. designed research; S.W., D.T., N.G., T.M., E.M., J.T., G.M., R.G., H.A., and Z.K. performed research; S.W., D.T., T.M., E.M., and Z.K. analyzed data; S.W., O.L., M.S., and Z.K. wrote the paper.

This work was supported by European Union Project TargetBraln Grant 279017, the Swedish Research Council, the AFA Foundation, the Ragnar Söderberg Foundation, and the Swedish Government Initiative for Strategic Research Areas (StemTherapy). S.W. and T.M. were partly supported by the Program of Strategic Scholarships for Frontier Research Network, Thailand's Office of the Higher Education Commission, and Shota Rustaveli National Science Foundation (Tbilisi, Georgia), respectively. We thank Dr. Talia Velasco for help with monocyte isolation, Zhi Ma and Teona Roschupkina for help with cell sorting, and Linda Jansson for technical assistance.

The authors declare no competing financial interests. trating from the circulation (Gelderblom et al., 2009; Shechter et al., 2009; Faustino et al., 2011; Chu et al., 2014; Benakis et al., 2015; Miró-Mur et al., 2016). Recent studies in other models of acute CNS injuries, as well as in chronic neurodegenerative diseases, have highlighted the pivotal role of the infiltrating MDMs in the repair process in addition to that of microglia and have emphasized that these two myeloid populations display nonredundant functions (Shechter et al., 2009, 2013; Mitchell et al., 2014; van Ham et al., 2014; Franco and

Correspondence should be addressed to Dr. Zaal Kokaia, Laboratory of Stem Cells and Restorative Neurology, Lund Stem Cell Center, University Hospital, SE-22184 Lund, Sweden. E-mail: zaal.kokaia@med.lu.se.

S. Wattananit's present address: Department of Clinical Sciences and Public Health Medicine, Faculty of Veterinary Science, Mahidol University, Nakorn Prathom 73170, Thailand.

D0I:10.1523/JNEUROSCI.4317-15.2016

Copyright $@ 2016$ the authors $\quad 0270-6474 / 16 / 364182-14 \$ 15.00 / 0$ 
Fernández-Suárez, 2015). In a model of spinal cord injury, MDMs, which locally display anti-inflammatory activities, are required to resolve the local inflammation and to facilitate scar resolution (Shechter et al., 2013). Both the local inflammation and the scar are essential interim stages in the repair process, yet their timely resolution is critical, and if it does not occur in a timely manner, chronic inflammation and impaired functional recovery may ensue (Clark et al., 1993; Rolls et al., 2008).

Outside the CNS, resolution of inflammation is an active process that involves myeloid cells of distinct phenotypes, which could reflect either recruitment of different cells with distinct phenotypes or local conversion of cells from a proinflammatory to an anti- inflammatory phenotype (Ksander et al., 1991; London et al., 2011). For myeloid cells to benefit repair, their presence and distinct activities should be well orchestrated in synchrony with the tissue needs (Shechter and Schwartz, 2013; Raposo et al., 2014; Gadani et al., 2015). Such an understanding is now widely appreciated in several models of neurodegenerative conditions (Yong and Rivest, 2009; Hu et al., 2015).

The role of myeloid cells in the functional recovery process after stroke is poorly understood. In hemorrhagic stroke, MDMs are needed to promote vascular healing (Gliem et al., 2012), yet the involvement of MDMs in the repair processes beyond the acute phase, at the remodeling stage, and during long-term functional restoration has not been studied.

The objectives of the present study were two-fold: (1) to explore the contribution of infiltrating MDMs to long-term spontaneous functional recovery after stroke; and (2) to characterize the phenotype and possible mechanisms of action of recruited monocytes during poststroke recovery.

We show that MDMs infiltrate the sites of ischemic stroke and that a switch of their phenotype occurs from proinflammatory to anti-inflammatory with time after injury. Most importantly, we demonstrate that depletion of monocytes from the circulation at the early stage after the ischemic event, resulting in limited MDM recruitment to the site of lesion, leads to impaired recovery of sensorimotor function as assessed at the chronic phase after stroke. Our findings suggest that timely recruitment of immune cells is critical for spontaneous long-term recovery.

\section{Materials and Methods}

Animals. All procedures were performed in accordance with the guidelines set by the Malmö-Lund Ethical Committee for the use of laboratory animals and were conducted in accordance with the European Union directive on the subject of animal rights. Stroke surgeries were performed on male C57BL/6J and B6SJL (CD45.1) mice (25-30 g; Charles River), and CX3CR1-EGFP (CD45.2) and $\beta$-actin-GFP ${ }^{+}$C57BL/C mice were used as donors for bone marrow and monocyte transplantation, respectively. All animals were kept in $12 \mathrm{~h}$ light/dark cycles. Food and water were provided ad libitum except during behavioral tests when mice were kept under food restriction to raise their motivation.

Chimera generation. Bone marrow chimeric mice were prepared by subjecting recipients to myeloablative treatment through whole-body irradiation with $10 \mathrm{~Gy}$ with head protection. All mice were transferred to a sterile condition. Antibiotic supplements in drinking water were provided from 1 week before and at least 1 week after myeloablation. Bone marrow cells were collected from CX3CR1-EGFP donors and purified on the day of transplantation. Briefly, the tibia and femur were entirely removed from the fresh cadaver. Bone marrow was flushed out with 5\% fetal bovine serum (FBS) in Dulbecco's PBS (DPBS) using a needle placed at an end of the bone. Cell preparation was filtered through sterile $35 \mu \mathrm{m}$ nylon mesh and washed three times by $10 \mathrm{~min}$ centrifugation at $300 \times g$, and pellet was resuspended with FBS-free DPBS. The total number of cells was evaluated during washing, and the desired concentration was prepared after the last centrifugation. Between 4 and $12 \mathrm{~h}$ after irradiation, $2 \times 10^{7}$ cells in $200 \mu$ l were injected in the tail vein of recipients. Hydration status was monitored carefully during 2 weeks after transplantation.

Middle cerebral artery occlusion. Stroke was induced using the intraluminal filament model of middle cerebral artery occlusion (MCAO) as described previously in mice (Hara et al., 1996; Andsberg et al., 2001). The right common carotid artery (CCA) and its proximal branches were isolated. The CCA and external carotid artery (ECA) were ligated, and the internal carotid artery (ICA) was temporarily occluded using a metal microvessel clip. A nylon monofilament was advanced through the ICA until resistance was felt ( $\sim 9 \mathrm{~mm}$ distance). The nylon filament was carefully removed after 30 min occlusion, ECA was ligated permanently, and the surgical wound was closed. In sham-operated animals, the filament was advanced only a few millimeters inside the ICA. Special care was taken during 1 week after surgery. A high-calorie gel diet (DietGel Boost; $\mathrm{ClearH}_{2} \mathrm{O}$ ) was supplemented, and Ringer's solution was injected subcutaneously daily in case of dehydration. Animals were allocated randomly to stroke or sham surgery and to the different experimental groups.

Monocyte transplantation. Bone marrow cells were collected from CX3CR1-EGFP (CD45.2) or $\beta$-actin-GFP ${ }^{+}$C57BL/C donor mice by crushing the femurs, tibiae, and hips. Cells were passed through a $50 \mu \mathrm{m}$ pore diameter strainer and rinsed with DPBS supplemented with $2 \%$ FBS. CD $115^{+}$cells were isolated using a magnetic cell separation system and biotinylated anti-CD115 antibody combined with streptavidinmagnetic beads (Miltenyi Biotec).

Behavioral tests. Staircase and corridor tests were performed by researchers blinded to the three experimental groups: (1) sham-treated and vehicle-injected ("sham"); (2) stroke-subjected and vehicle-injected ("vehicle"); and (3) stroke-subjected and MC-21-injected ("MC-21").

The staircase test was used to assess "side-specific" skilled forelimb reaching and grasping abilities (Montoya et al., 1991; Baird et al., 2001) in a staircase apparatus (Campden Instruments). Briefly, animals were food deprived $12 \mathrm{~h}$ before the first testing day and kept on a restricted food intake $(2.5-3.5 \mathrm{~g} / \mathrm{d})$ so that the body weight did not fall below $85 \%$ of initial value. Food was provided only after the daily test session. When testing, animals were placed in Plexiglas boxes holding a removable double staircase, with two chocolate pellets (TestDiet) placed on each of steps 3 to 8 on both sides (total of 12 pellets/side). During each session, animals were kept in the box for 15 min once a day, after which the number of pellets retrieved and eaten on each side was calculated. Retrieved pellet was identified as pellets that had been removed from the original step, regardless of whether or not the pellet had been eaten. Before MCAO, mice were tested for 12 consecutive days. The Mean number of retrieved and eaten pellets from the last $3 \mathrm{~d}$ was used as the preinsult performance score. At weeks 1, 3, and 7 after MCAO, mice were retested for $5 \mathrm{~d}$ using the same method, and the average of the last $3 \mathrm{~d}$ was calculated.

The corridor test (Dowd et al., 2005), adapted to mice (Grealish et al., 2010), was used to assess sensorimotor impairment caused by striatal damage. Briefly, mice were food restricted in the same manner as in staircase test throughout habituation and testing. At the first time point, mice were habituated to the corridor by scattering sugar pellets along the floor and allowing them to freely explore for $10 \mathrm{~min}$ on 2 consecutive days before testing. When testing began, the mice were transferred to one end of the testing corridor. The number of ipsilateral and contralateral retrievals was counted until the mouse made a total of 20 retrievals or a maximum time of $5 \mathrm{~min}$ had elapsed. A "retrieval" was defined as an exploration into a pot, whether or not a pellet was eaten, and a new retrieval could only be made by investigating a new pot. Retrieval average was calculated from last 3 testing days. Data are expressed as percentage contralateral (relative to lesion) retrievals, calculated as the number of contralateral retrievals in percentage of the total retrievals made from both sides. Results from later tests, weeks 1, 3, 7, and 11 after MCAO, were used as the poststroke performance score.

Flow cytometry. Blood sample collection and flow cytometry were performed by researchers blinded to the identity of the groups. Peripheral blood was collected from the tail vein of mice at days $4,7,10$, and 14 after MCAO. Erythrocytes were lysed with ammonium chloride. Leukocyte single-cell suspensions were analyzed using the following antibodies: CD45.1-Brilliant Violet 510 (Biolegend), CD45.2-Phycoerytrin-PE 
Table 1. Proinflammatory and anti-inflammatory genes analyzed for expression in ipsilateral and contralateral brain hemispheres at 3, 7, and $14 \mathrm{~d}$ after stroke

\begin{tabular}{lll}
\hline Gene name & Gene type & TaqMan probe number \\
\hline IL-6 & Proinflammatory & Mm00446190_m1 \\
IL-13 & Proinflammatory & Mm00434204_m1 \\
IL-1 $\beta$ & Proinflammatory & Mm00434228_m1 \\
N0S2 & Proinflammatory & Mm00440502_m1 \\
IL12 $\alpha$ & Proinflammatory & Mm00434165_m1 \\
TNF $\alpha$ & Proinflammatory & Mm00443258_m1 \\
VCAM1 & Anti-inflammatory & Mm01320970_m1 \\
CCL22 & Anti-inflammatory & Mm00436439_m1 \\
BDNF & Anti-inflammatory & Mm04230607_s1 \\
VEGF $\alpha$ & Anti-inflammatory & Mm01281449_m1 \\
IGF1 & Anti-inflammatory & Mm00439560_m1 \\
CD163 & Anti-inflammatory & Mm00474091_m1 \\
YM1(Chil3) & Anti-inflammatory & Mm00657889_mH \\
TGF $\beta 1$ & Anti-inflammatory & Mm01178820_m1 \\
TGF $\beta 2$ & Anti-inflammatory & Mm00436955_m1 \\
Arg1 & Anti-inflammatory & Mm00475988_m1 \\
PPARY & Anti-inflammatory & Mm01184322_m1 \\
IL10 & Anti-inflammatory & Mm00439614_m1 \\
CXCL13 & Anti-inflammatory & Mm04214185_s1 \\
HPRT & Housekeeping & Mm03024075_m1 \\
GAPDH & Housekeeping & Mm99999915-g1 \\
\hline
\end{tabular}

(Biolegend), CD45-Brilliant Violet 510 (Biolegend), CD11b-Brilliant Violet 421 (Biolegend), Ly6C-Alexa Fluor 700 (BD Bioscience), CD115APC (BD Bioscience), CCR2-Fluorescin-FITC (R\&D Systems), and CX3CR1-Phycoerythrin-PE (R\&D System). Flow cytometry was performed with FACSAria III cell sorter (BD Biosciences) or LSR II analyzer (BD Bioscience), following the specifications for each fluorophore. Data were analyzed using FlowJo software (FlowJo).

For brain tissue analysis, animals were sublethally anesthetized by intraperitoneal injection of pentobarbital. Mice were then perfused transcardially with sterile cold saline solution until the blood was completely washed out. Brains were quickly removed and placed in cold hibernation medium (Kawamoto and Barrett, 1986). Brains were dissociated using Neural Tissue Dissociation kit (Miltenyi Biotec) according to the instructions of the manufacturer. Myelin debris was removed by using magnetic beads (Miltenyi Biotec). Cells were stained and analyzed following the same protocol as for blood samples.

$M C-21$ injection. Production of the anti-CCR2 monoclonal antibody MC-21 was performed as described previously (Mack et al., 2001). MC-21 was used to selectively deplete $\mathrm{CD} 115^{+} / \mathrm{CD} 11 \mathrm{~b}^{+} / \mathrm{Ly} 6 \mathrm{C}^{+}$monocytes from the blood. MC-21 was injected intraperitoneally immediately after MCAO and on the first $3 \mathrm{~d}$ of recovery (days $0,1,2$, and 3 after injury). We initially tested whether isotype control for MC-21 antibody (Rat IgG2b; BD Pharmingen) or PBS injections with the same regimen and volume as for MC-21 antibody would affect the number of circulating CCR2 ${ }^{+}$monocytes in stroke-subjected animals. We observed no differences between the control antibody- and PBS-injected groups, and, therefore, we used PBS injection as vehicle and treatment control in all experiments.

RNA extraction and quantitative PCR. Brain dissection and gene expression analysis were performed by researchers blinded to the groups. Mice were deeply anesthetized and perfused transcardially with heparinized saline. Brains were dissected, the forebrain was isolated from meninges, and hemispheres ipsilateral (right) and contralateral (left) to injury were separated. Total RNA was extracted from the tissue using RNeasy mini kit (Qiagen) and then reversed to cDNA using Quanta qScript cDNA Synthesis kit (Quanta Biosciences). For quantitative PCR, TaqMan Gene expression master mix (Life Technologies) and TaqMan assays for proinflammatory and anti-inflammatory genes (Table 1) were used. Cycle threshold values of target genes were normalized to geometric mean of housekeeping hypoxanthine phosphoribosyltransferase (HPRT) and GAPDH.

Immunocytochemistry. Mice were deeply anesthetized with an overdose of pentobarbital and perfused transcardially with cold saline solu-
Table 2. Primary antibodies used for immunocytochemistry

\begin{tabular}{llll}
\hline Antibodies & Host species & Dilution & Company \\
\hline BDNF & Rabbit & $1: 200$ & Alomone Labs \\
CD31 & Rat & $1: 400$ & BD Pharmingen \\
CD68 (ED1) & Rat & $1: 200$ & AbD Serotec \\
GFAP & Rabbit & $1: 400$ & Zymed (Invitrogen) \\
GFP & Chicken & $1: 3000$ & Millipore \\
IB4-FITC conjugated & Lectin from Bandeiraea simplicifolia & $1: 50$ & Sigma-Aldrich \\
Iba1 & Goat & $1: 200$ & AbD Serotec \\
IL-6 & Rabbit & $1: 300$ & Abcam \\
NeuN & Mouse & $1: 100$ & Millipore \\
TGF $\beta$ & Mouse & $1: 300$ & R\&D Systems \\
\hline
\end{tabular}

tion, followed by $4 \%$ cold paraformaldehyde (PFA). Brains were postfixed overnight in 4\% PFA and then placed in 20\% sucrose for $24 \mathrm{~h}$ before coronal sectioning ( $30 \mu \mathrm{m}$ thickness) on dry ice. Sections were preincubated in blocking solution (5\% normal serum and $0.25 \%$ Triton X-100 in $0.1 \mathrm{M}$ potassium-buffered PBS). Primary antibodies (Table 2) were diluted in the blocking solution and applied overnight at $4^{\circ} \mathrm{C}$. Corresponding fluorophore-conjugated secondary antibodies (Invitrogen or The Jackson Laboratory) were diluted in blocking solution and applied for $2 \mathrm{~h}$, followed by three rinses in potassium-PBS.

Single labeling for NeuN was performed with biotinylated horse antimouse antibody and visualized with avidin-biotin-peroxidase complex (Elite ABC kit; Vector Laboratories), followed by peroxidase-catalyzed diaminobenzidine reaction.

Quantifications and statistical analysis. All quantifications and statistical analyses were performed by researchers blinded to the experimental groups. Counting of infiltrated monocytes was performed in GFPstained sections. Whole-hemisphere images were acquired digitally using epifluorescence microscopy and cellSens Dimension version 1.8 software (Olympus Corporation). The number of immunopositive cells was estimated by a threshold-based object detection analysis method.

The numbers of $\mathrm{ED} 1^{+}$and ionized calcium-binding adapter molecule 1 -positive $\left(\mathrm{Ibal}^{+}\right)$cells were quantified in the ipsilateral striatum in three coronal sections at $+0.62,+0.86,+1.1 \mathrm{~mm}$ from bregma using an epifluorescence microscope with $40 \times$ objective. $\mathrm{Ibal}^{+}$and $\mathrm{Ibal}^{+} /$ $\mathrm{ED} 1^{+}$cells were counted within a column of four continuous fields using a $0.25 \times 0.25 \mathrm{~mm}^{2}$ quadratic grid placed in the non-infarcted area next to the subventricular zone with the uppermost grid located just below the corpus callosum.

For lesion volume estimation, images of NeuN-DAB-stained sections were first taken under $4 \times$ magnification. Intact areas identified by $\mathrm{NeuN}^{+}$cells in the ipsilateral and contralateral hemispheres were delineated and then measured using Visiopharm software. The area of unlesioned tissue in the ipsilateral hemisphere was subtracted from that of the contralateral hemisphere to get the infarct area, and this area was subsequently multiplied by the distance between the sections $(240 \mu \mathrm{m})$ to get the infarct volume.

Comparisons were performed using GraphPad Prism version 6.05 (GraphPad Software) by one-way or two-way ANOVA, followed by Bonferroni's multiple comparisons test, or Student's unpaired $t$ test. Data are presented as means \pm SEMs, and differences are considered significant at $p<0.05$.

\section{Results}

Transplanted and endogenous monocytes are recruited to injured brain tissue after stroke

We first assessed whether monocytes home to sites of injury in the stroke-affected brain. To be able to trace the monocytes and identify their homing site, we passively transferred homologous monocytes isolated from the bone marrow of $\beta$-actin- $\mathrm{GFP}^{+} \mathrm{C} 57 \mathrm{BL} / \mathrm{C}$ mice into syngenic wild-type mice that do not express GFP. This allows distinction between infiltrating monocytes and resident activated microglia. Two groups of animals were subjected to MCAO and on the next day injected through the tail vein with 4 million $\mathrm{GFP}^{+}$/ 

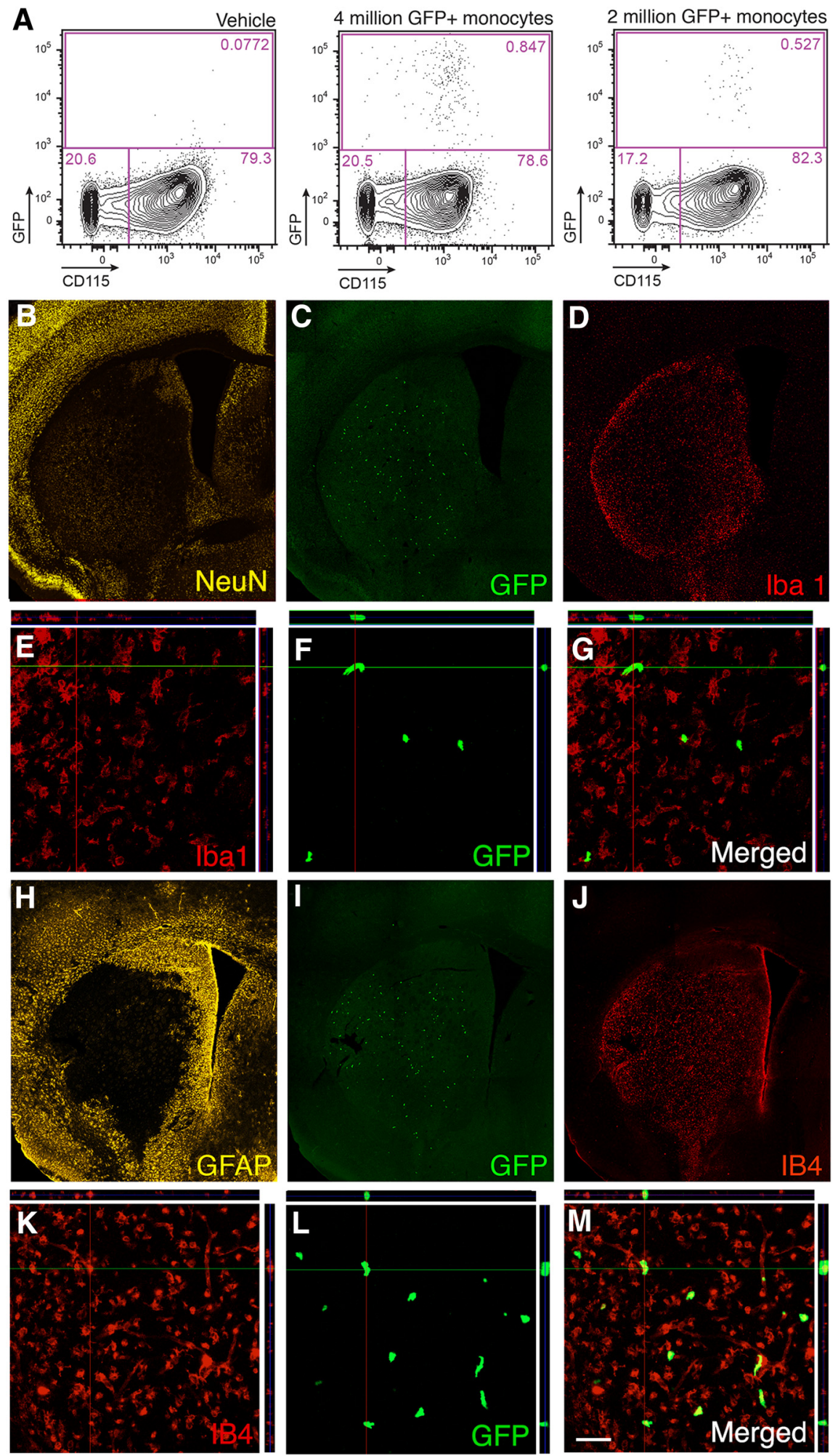

Figure 1. Transplanted and endogenous monocytes are recruited to injured brain tissue after stroke. $\boldsymbol{A}$, Flow cytometry analysis of blood samples from animals injected intravenously $1 \mathrm{~d}$ after MCA0 with either vehicle $(n=2)$ or with $2(n=4)$ or $4(n=4)$ million GFP ${ }^{+}$monocytes and killed 2 later. $\boldsymbol{B}-\boldsymbol{G}$, Fluorescence microscopic images of mouse brain coronal sections showing the ischemic lesion in the striatum visualized by NeuN staining $(\boldsymbol{B})$, distribution of grafted GFP ${ }^{+}$monocytes within the lesion $(\boldsymbol{C}, \boldsymbol{F})$, and expression of Iba1 $(\boldsymbol{D}, \boldsymbol{E})$ by cells within the injured striatum. $\boldsymbol{E}-\boldsymbol{G}$, Confocal images showing $\mathrm{GFP}^{+}$grafted monocytes in the lesioned striatum $(\boldsymbol{F})$ not expressing lba1 $(\boldsymbol{E})$ with merged image in $\boldsymbol{G}$. $\boldsymbol{H}-\boldsymbol{K}$, Fluorescence microscopic images of mouse brain coronal sections showing extensive GFAP staining mostly outside the lesion $(\boldsymbol{H})$, distribution of grafted GFP ${ }^{+}$monocytes within the lesion $(\boldsymbol{I})$, and expression of IB4 $(\boldsymbol{J}, \boldsymbol{K})$ by cells within the injured striatum. $\boldsymbol{L}, \boldsymbol{M}$, Confocal images showing GFP ${ }^{+}$grafted monocytes in the lesioned striatum ( $\boldsymbol{L}$ ) expressing activation marker IB4 (I) with merged image in $\boldsymbol{M}$. Scale bar (in $\boldsymbol{M}$ ): $\boldsymbol{B}-\boldsymbol{D}, \boldsymbol{H}-\boldsymbol{J}$, $420 \mu \mathrm{m} ; \boldsymbol{E}-\mathbf{G}, \boldsymbol{K}-\boldsymbol{M}, 50 \mu \mathrm{m}$.
$\mathrm{CD} 115^{+}$monocytes or vehicle, respectively. The purity of the $\mathrm{CD} 115^{+}$population was $94-98 \%$ as defined by flow cytometry. Two days later, blood samples and brain tissue (ipsilateral and contralateral hemispheres separately) were taken for analysis by flow cytometry, and some animals were processed for immunocytochemistry. At this time point, the $\mathrm{GFP}^{+} / \mathrm{CD} 115^{+}$grafted monocytes constituted $0.85 \%$ of all $\mathrm{CD} 115^{+}$monocytes in the blood, whereas in vehicle-injected animals, only very few autofluorescent events were recorded (Fig. 1A).

Immunocytochemistry revealed that grafted $\mathrm{GFP}^{+}$monocytes were located exclusively in the ipsilateral hemisphere, the overall majority within the ischemically injured striatum (Fig. 1B,C,I). Approximately $6000 \mathrm{GFP}^{+}$cells per brain were found (Fig. 1C). The injured striatum was filled with cells immunoreactive for the microglia marker Ibal (Fig. 1D). Most likely, these cells were resident microglia because freshly recruited monocytes are not $\mathrm{Ibal}^{+}$, and, moreover, not a single $\mathrm{GFP}^{+}$cell showed Ibal immunoreactivity (Fig. $1 E-G)$. The vast majority $(>80 \%)$ of the $\mathrm{GFP}^{+}$cells were positive for the activated macrophage marker isolectin (IB4; Fig. $1 J-M)$, providing evidence that they had become activated macrophages.

We then assessed whether the number of recruited transplanted cells reflects their incidence in the blood. To this end, a group of mice was injected with 2 million $\mathrm{GFP}^{+}$ monocytes, i.e., half the number compared with the initial experiment in which 4 million cells were injected. Interestingly, at day 3 after stroke, the $\mathrm{GFP}^{+} / \mathrm{CD} 115^{+}$ grafted monocytes constituted $0.53 \%$ of all $\mathrm{CD}_{115}{ }^{+}$monocytes in the blood (Fig. 1A), and we detected approximately half the number of $\mathrm{GFP}^{+}$cells per brain in animals injected with 2 million compared with 4 million cells. Virtually all GFP ${ }^{+}$monocytes that infiltrated to the brain were localized within the injured tissue (Fig. $1 C, F$ ). These findings indicate that the number of monocytes homing to the ischemic lesion correlates with the number of CD $115^{+}$circulating monocytes.

To validate these data and estimate the ratio between microglia and infiltrating grafted and endogenously recruited monocytes, we repeated the same transplantation paradigm as in the previous experiment and administered 4 million monocytes from CD45.2 mice to stroke-subjected CD45.1 mice. Microglia and infiltrating, endogenously recruited or grafted MDMs were then distinguished based on levels of CD45, being low and high, respectively (Sedgwick 


\section{A Contralateral}
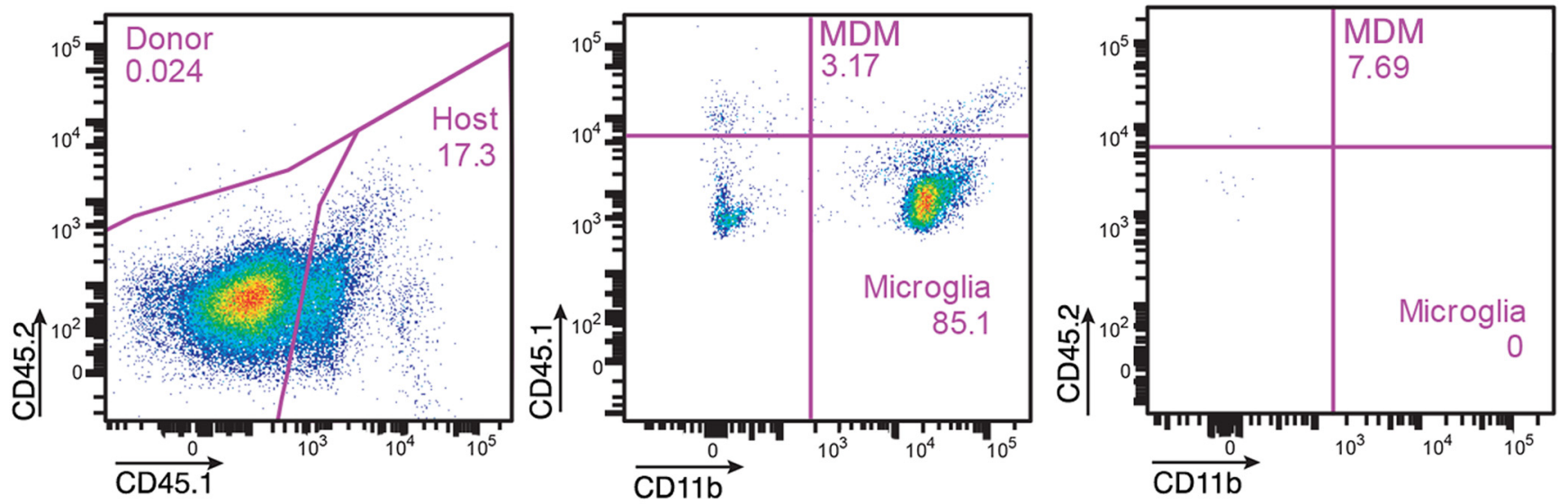

B Ipsilateral
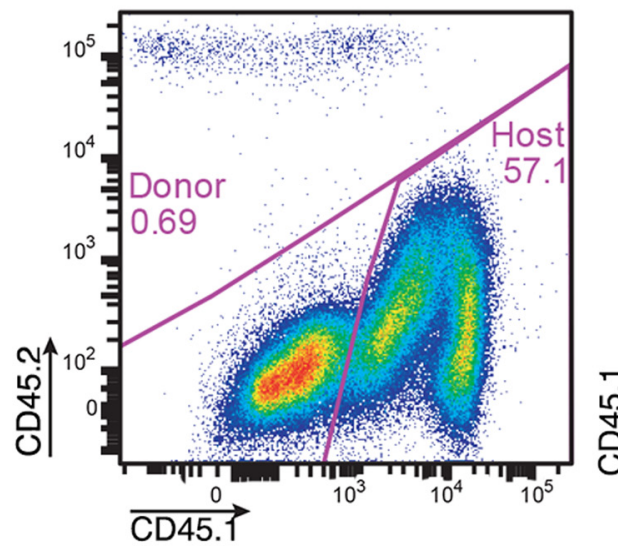

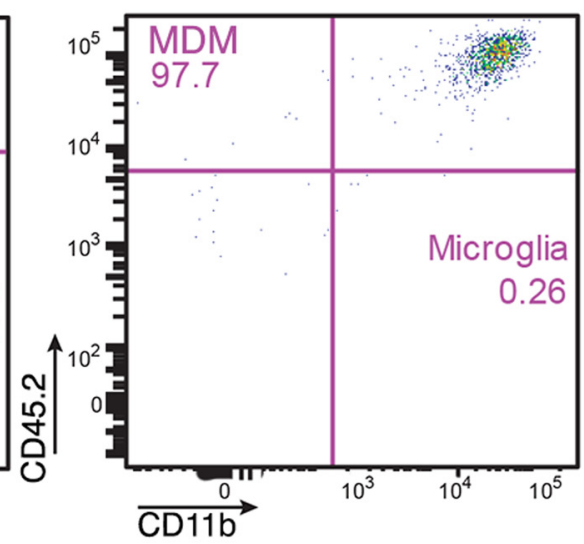

Figure 2. Flow cytometry analysis of brain hemispheres [contralateral $(\boldsymbol{A})$ and ipsilateral $(\boldsymbol{B})$ to the lesion] from CD45.1 mice subjected to MCA0 and injected intravenously with 4 million

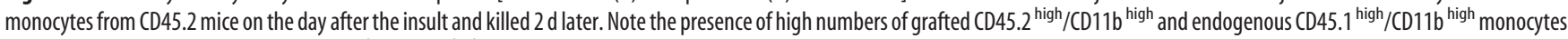
ipsilateral to the ischemic lesion. The CD45.1 ${ }^{\text {low }} /$ CD $11 b^{\text {high }}$ cells are microglia.

et al., 1991; Shechter et al., 2013). In the contralateral, intact hemisphere (Fig. $2 A$ ), the MDMs (CD45.1 ${ }^{\text {high }}$ ) constituted $\sim 3 \%$ of all $\mathrm{CD} 11 \mathrm{~b}^{+}$cells, but there were virtually no grafted CD $45.2^{+} \mathrm{MDMs}$. The vast majority $(85.1 \%)$ of CD $11 b^{+}$cells were resident CD $45.1^{\text {low }}$ microglia. In the ipsilateral hemisphere, we detected a small population $\left(0.69 \%\right.$ of all CD $45^{\text {high }}$ cells) of CD $45.2^{\text {high }}$ grafted MDMs (Fig. $2 B)$. However, they were extremely few compared with the infiltrated, endogenously recruited CD $45.1^{\text {high }}$ MDMs, which represented approximately half of all $\mathrm{CD} 11 \mathrm{~b}^{+}$cells. Together, our data show that, within $2 \mathrm{~d}$ after transplantation, the grafted monocytes home to the stroke-injured hemisphere, in which they represent only a very small fraction of $\mathrm{CD} 11 \mathrm{~b}^{+}$microglia and are much fewer than endogenously derived monocytes.

Infiltration of endogenous circulating monocytes peaks at $3 \mathrm{~d}$ after stroke

To explore in detail the extent and dynamics of spontaneous monocyte infiltration to the stroke-injured brain, we killed mice at different time points after stroke and analyzed by flow cytometry the myeloid cell composition in both hemispheres (Fig. $3 A$ ).

We found that the numbers of spontaneously infiltrating MDMs in the hemisphere ipsilateral to the insult reached a peak ( $>60$-fold increase compared with the hemisphere on contralateral side or in intact or sham-treated animals) at $3 \mathrm{~d}$ after stroke and then declined rapidly, still being higher at $7 \mathrm{~d}$ compared with contralateral side but reaching control values at $14 \mathrm{~d}$ (Fig. $3 \mathrm{~B}$ ).

The numbers of MDMs in sham-operated and intact mice at $1 \mathrm{~d}$ after treatment (Fig. 3B) were similar to those after stroke in the ipsilateral hemisphere on the day of the injury and in the contralateral hemisphere at all tested time points (Fig. $3 A, B$ ). We assumed that the majority of these cells were residual blood monocytes in brain capillaries. We stained the brains of shamoperated animals with CD31 as a marker for vessels, IB4 for activated macrophages, and Ibal as a microglia/macrophage marker (Fig. $3 C$ ). In support of our contention, the IB4 ${ }^{+}$monocytes were clearly located within the blood vessel lumen, whereas the $\mathrm{Iba1}^{+}$microglia, exhibiting ramified resting phenotype, were found in the brain parenchyma.

Depletion of circulating monocytes during the first week after stroke impairs long-term spontaneous recovery

To explore the potential role of MDMs for spontaneous functional recovery after stroke, we depleted circulating monocytes during the first week after the insult, i.e., at a time when maximum monocyte infiltration takes place. We selectively depleted $\mathrm{Ly}_{6 \mathrm{C}}{ }^{+} / \mathrm{CCR} 2{ }^{+}$monocytes from peripheral blood using the antiCCR2 antibody MC-21 (Mack et al., 2001; Shechter et al., 2009). The CCR2 receptor is the binding site for the CCL2 ligand (also 

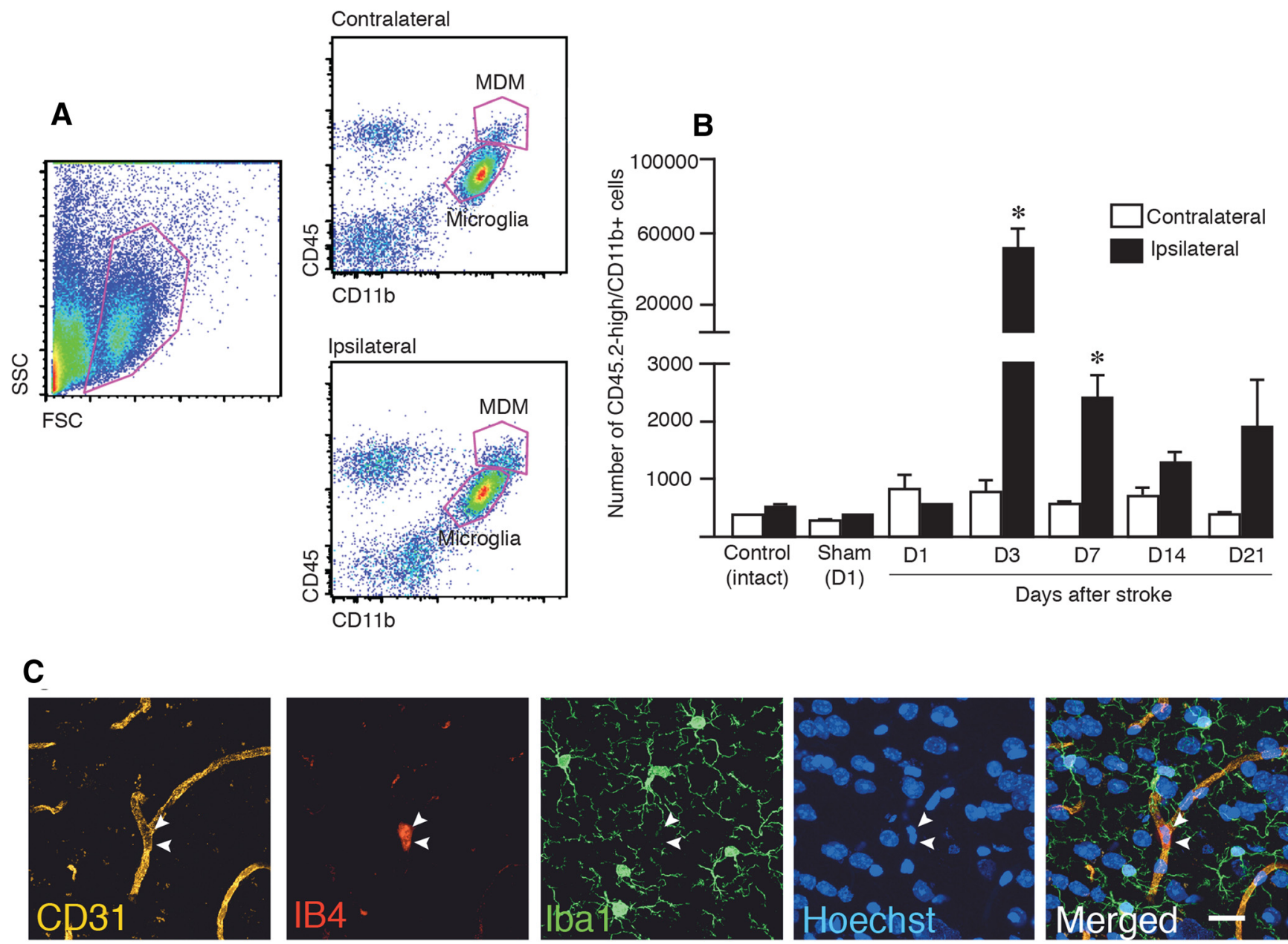

Figure 3. Spontaneous infiltration of circulating monocytes to the sites of lesion peaks at $3 \mathrm{~d}$ after stroke. $A$, Examples of flow cytometry analysis of brain hemispheres (contralateral and ipsilateral to lesion) of mice subjected to MCA0, identifying MDMs and microglia as $C D 45^{\text {high }} / C D 11 b^{\text {high }}$ and CD45 ${ }^{\text {low }} / C D 11 b^{\text {high }}$, respectively. $\boldsymbol{B}$, Time course of numbers of MDMs based on flow cytometry analysis in hemispheres contralateral and ipsilateral to MCAO or sham treatment and in control hemisphere. Numbers of animals: Control, $n=4 ; \operatorname{Sham}, n=3 ; \mathrm{D} 1, n=3 ; \mathrm{D} 3, n=12 ; \mathrm{DT}, n=7$; $\mathrm{D} 14, n=5 ;$ and D21, $n=6$. Data are means $\pm \mathrm{SEMs} ;{ }^{*} p<0,05$, paired $t$ test between contralateral and ipsilateral sides for each group. C, Fluorescence microscopic images of mouse brain showing $\mathrm{CD} 31^{+}$vessel, IB4 ${ }^{+}$activated monocytes, Iba ${ }^{+}$microglia, Hoechst ${ }^{+}$nuclei in the striatum of sham-treated animal, and merged image. D, Day; SSC, side scatter; FSC, forward scatter. Scale bar, $20 \mu \mathrm{m}$.

known as monocyte chemoattractant protein-1 or MCP-1), which mediates monocyte egress from the bone marrow to the circulation. Also, the CCR $2^{+}$cells are the ones recruited to injured tissues outside (Wetzler et al., 2000; Peters and Charo, 2001; Peters et al., 2001; Bose and Cho, 2013) and to the CNS (Yan et al., 2007; Shechter et al., 2009; Prinz and Priller, 2010; Saederup et al., 2010). Animals were subjected to stroke and injected with MC-21 antibody the same day and at 1,2, and $3 \mathrm{~d}$ after the insult. Shamtreated and stroke-subjected mice were injected with vehicle and served as controls. Blood samples collected at $4 \mathrm{~d}$ after stroke ( $1 \mathrm{~d}$ after the last injection of $\mathrm{MC}-21$ ) revealed nearly complete loss of circulating monocytes in all MC-21-treated animals (Fig. 4A). At $10 \mathrm{~d}$, the CCR2 ${ }^{+}$monocytes in peripheral blood had started to rebound and at $14 \mathrm{~d}$ had returned to normal level. Thus, the systemic administration of MC-21 antibody efficiently depleted circulating monocytes during the first week after stroke, as observed previously in other models of CNS insults (Shechter et al., 2009).

We next determined whether depletion of circulating CCR2 ${ }^{+}$ monocytes leads to reduction of the number of MDMs in the brain. Two groups of animals were subjected to stroke and injected with vehicle or MC-21 antibody as above. On day 3 after the insult, when in the previous experiment we had detected the highest level of infiltrating MDMs in the brain, we measured the effect of MC-21 antibody injection on numbers of blood CCR2 ${ }^{+}$ cells and infiltrating brain MDMs. The reduction of brain $\mathrm{CD} 45^{\text {high }} / \mathrm{CD} 11 \mathrm{~b}^{\text {high }} \mathrm{MDMs}$ in the MC-21 group was $86.8 \pm$ $5.8 \%$, which closely resembled the decrease of circulating CCR ${ }^{+}$ monocytes in the blood at the same time point $(89.9 \pm 1.5 \%)$. We found strong positive correlation $\left(R^{2}=0.90\right)$ between the blood level of infiltrating CCR $2{ }^{+}$monocytes and the number of MDMs (CD45 $5^{\text {high }} / \mathrm{CD} 11 \mathrm{~b}^{\text {high }}$ ) in the brain (Fig. $4 B$ ).

Based on these findings, we performed behavioral tests to assess how depletion of monocytes during the first week after stroke would affect the long-term functional recovery. All animals were subjected to corridor ( 1 week before and 1, 3, 7, and 11 weeks after stroke) and staircase tests (1 week before and 1, 3, and 7 weeks after stroke). Sham-treated animals showed normal behavior in corridor and staircase tests. We observed impairments in the corridor test on the contralateral side from 1 to 7 weeks after stroke in both vehicle- and MC-21-injected animals (Fig. 5A). Interestingly, at 11 weeks, we found spontaneous behavioral recovery, with the test performance reaching the control level, in vehicle-injected mice. In contrast, in MC-21-treated animals, the 
impairment was maintained at the same level as at earlier time points (Fig. 5A). In the staircase test, both vehicle- and MC21-injected mice showed a similar impairment in the number of retrieved pellets on the contralateral side at 1 week after stroke. At 3 weeks, the performance of the vehicle-injected mice did not differ from that of the sham-operated animals, whereas MC-21-treated mice still showed impairment. At 7 weeks, the number of retrieved pellets was similar in all three groups. These findings suggest a delayed recovery in this task in the monocytedepleted group. Similarly, when behavior in the staircase test was assessed by the number of eaten pellets, we found that the vehicle-injec-

ted group had recovered at 7 weeks, whereas the MC-21-injected animals remained impaired (Fig. 5C). To rule out the possibility that the worsening of longterm behavioral recovery in MC-21injected mice was an outcome of more extensive ischemic injury, we analyzed the lesion site by immunohistochemistry. NeuN-stained sections revealed no difference in infarct volume between the vehicle- and MC-21-treated groups at 18 weeks after stroke (Fig. 5D,E).

\section{MDMs switch bias from proinflammatory to anti-inflammatory activity during the first weeks after stroke}

To explore potential mechanisms underlying the recovery-promoting effect of MDMs, we first wanted to distinguish MDMs from activated microglia and determine their phenotype. Therefore, we generated chimeric mice by subjecting wild-type mice to bone marrow transplantation from CX3CR1-GFP mice. Notably, all mice were head protected during the irradiation that precedes the bone marrow transplantation (Shechter et al., 2009). In CX3CR1-GFP mice, CX3CR1 ${ }^{+}$monocytes and microglia are $\mathrm{GFP}^{+}$(Jung et al., 2000). However, in the chimeric animals, only bone marrow-derived monocytes are $\mathrm{GFP}^{+}$, which allows identification of MDMs with both immunocytochemistry and flow cytometry (Mildner et al., 2007).

Immunocytochemistry of brain sections from chimeric mice showed that, at $7 \mathrm{~d}$ after stroke, the majority of $\mathrm{GFP}^{+} \mathrm{MDMs}$ were distributed within the ischemically injured tissue, with some of them being localized in close proximity to the lesion border (Fig. 6A-C). This was in line with our previous experiments that showed that, already at $3 \mathrm{~d}$ after stroke, intravenously transplanted monocytes infiltrate the stroke-injured tissue (Fig. 1). The lesion border was clearly delineated by $\mathrm{GFAP}^{+}$activated astrocytes, most of which were found outside the lesion core (Fig. $6 B, C)$. The vast majority of the MDMs showed IB4 immunoreactivity (Fig. 6D). In brain tissue from the contralateral hemisphere or from sham-operated animals, virtually no $\mathrm{GFP}^{+}$bone marrow-derived monocytes were detected.
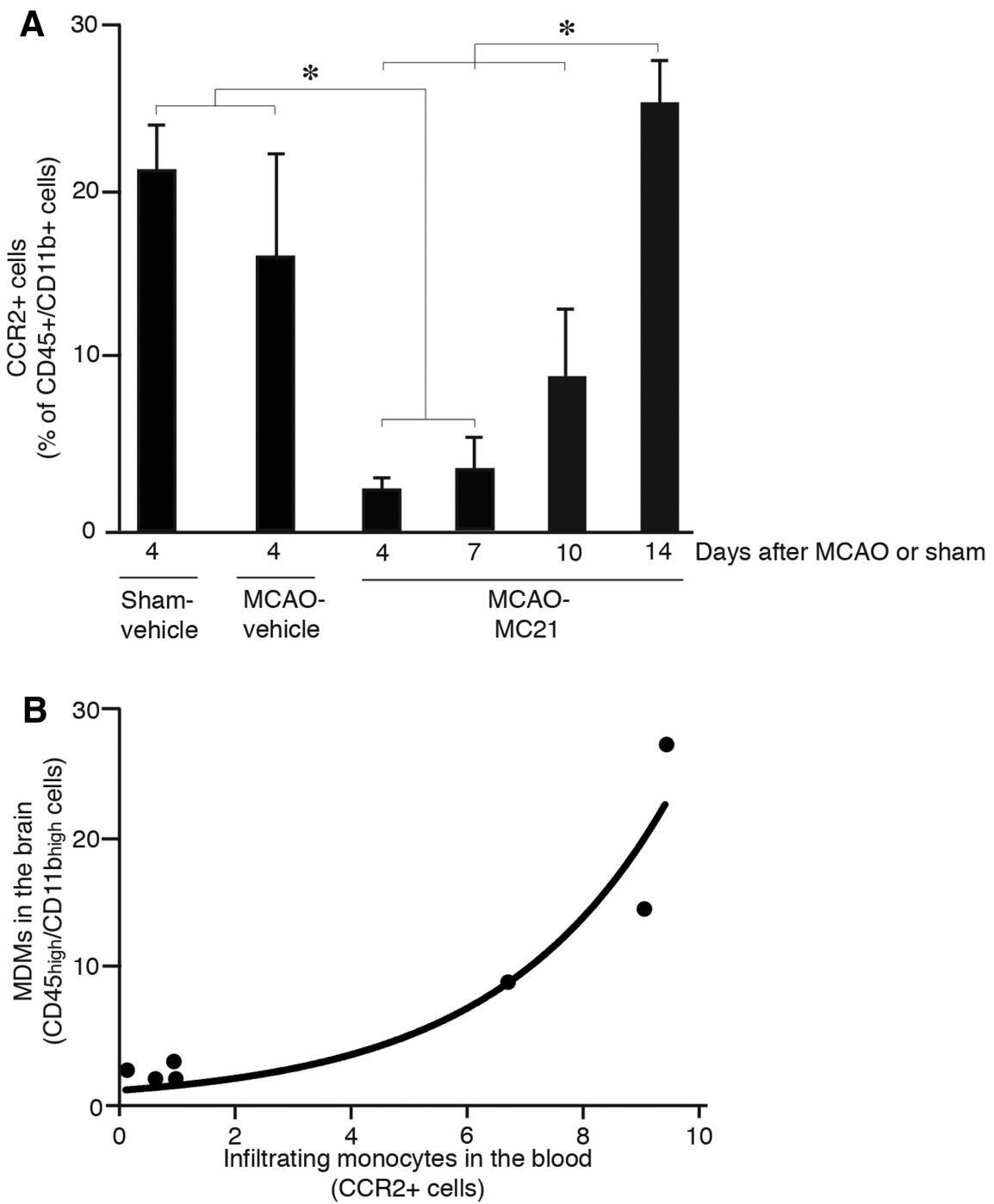

Figure 4. MC-21 antibody efficiently depletes circulating monocytes and MDMs in the brain. $A$, Numbers of circulating CCR2 ${ }^{+}$ Sham-vehicle, $n=9$; MCA0-vehicle, $n=9 ;$ Day 4, $n=13$; Day 7, $n=5$; Day $10, n=7$; and Day $14, n=8$. Data are means \pm EEMs; ${ }^{*} p<0.05$, one-way ANOVA. B, Correlation graph showing CCR2 ${ }^{+}$circulating monocytes expressed as percentage of CD45 high $/ C D 11 b^{\text {high }}$ blood monocytes and MDMs expressed as percentage of all CD45 ${ }^{+} / C_{1} 11 b^{+}$macrophages in brains of stroke-subjected mice, injected with either vehicle or MC-21 antibody $(n=7)$. Correlation analysis, $R^{2}=0.90, p<0.05$.

The flow cytometry analysis of tissue from the stroke-subjected mice confirmed that blood-borne monocytes had efficiently infiltrated only the injured hemisphere (Fig. 7A). Two major subpopulations of MDMs have been described previously: (1) the proinflammatory (Ly6C ${ }^{\text {high }}$ ) population; and (2) the alternatively activated anti-inflammatory population (Ly6C ${ }^{\text {low; }}$ Gordon and Taylor, 2005). We separated infiltrating MDMs and resident microglia based on CD45 and CD11b expression, and then we further separated the MDM population based on expression of CX3CR1 and Ly6C. We observed that the two subpopulations of MDMs in the brain after stroke, namely Ly6 $\mathrm{C}^{\text {high }} / \mathrm{CX} 3 \mathrm{CR} 1^{\text {low }}$ and $\mathrm{Ly} 6 \mathrm{C}^{\text {low }} /$ CX3CR $1^{\text {int }}$, underwent dramatic changes in the ipsilateral hemisphere: at the early time point (day 3 after injury), the relative percentage of the Ly6C $\mathrm{C}^{\text {high }} / \mathrm{CX} 3 \mathrm{CR} 1^{\text {low }} \mathrm{MDM}$ subpopulation was high but was then significantly reduced by day 7 . In contrast, the relative percentage of the $\mathrm{Ly} 6 \mathrm{C}^{\text {low }} / \mathrm{CX} 3 \mathrm{CR} 1{ }^{\text {int }}$ population remained relatively unchanged (Fig. $7 A$ ).

We further analyzed the phenotype of MDMs in intact and stroke-injured hemispheres at different time points after the in- 

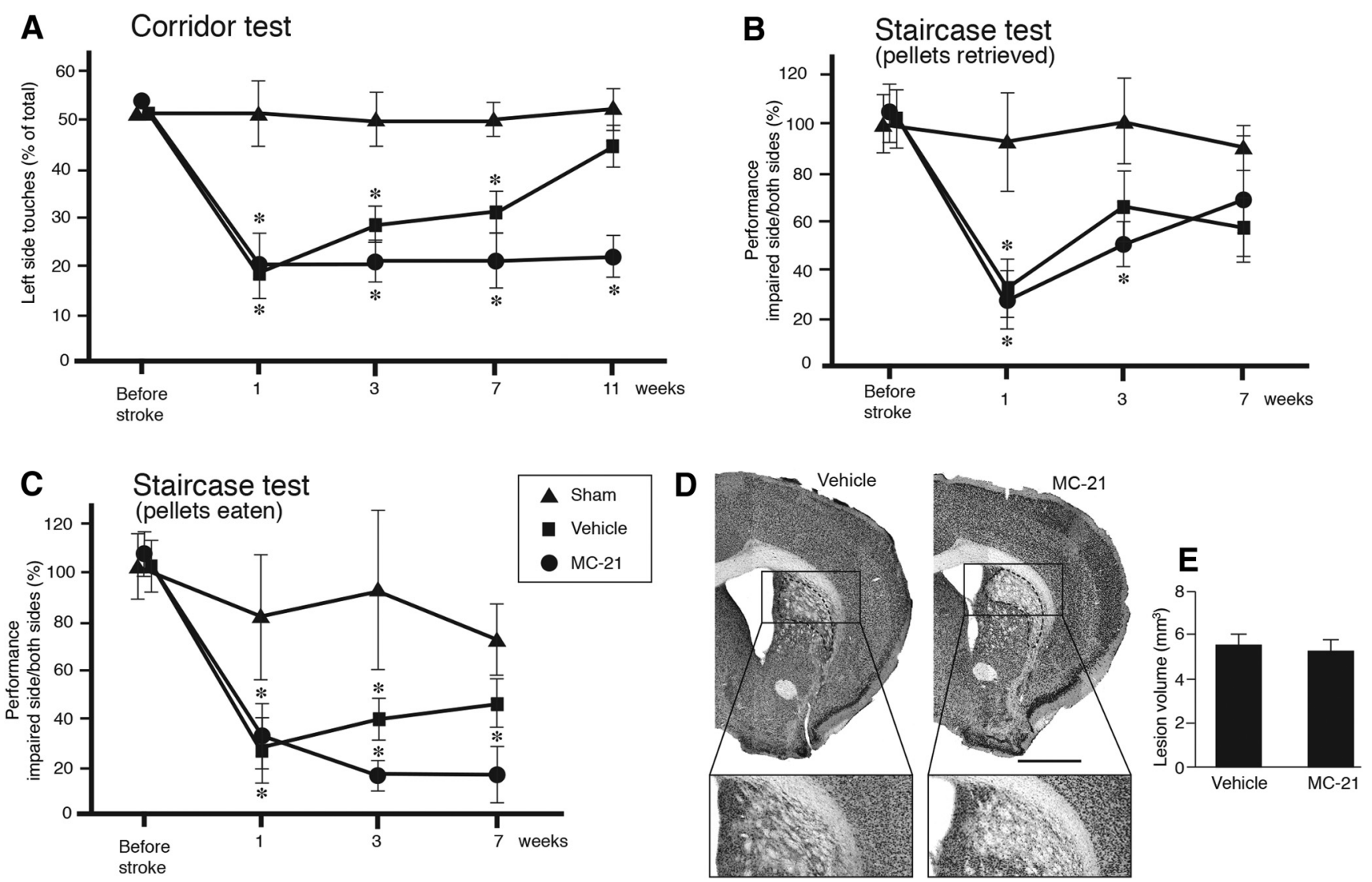

Figure 5. Depletion of circulating CCR2 ${ }^{+}$monocytes impairs long-term spontaneous behavioral recovery after stroke. $A-C$, Comparison between sham-treated and vehicle-injected (sham, $n=10$ ), stroke-subjected and vehicle-injected (vehicle, $n=9)$, and stroke-subjected and MC-21-injected (MC-21, $n=10)$ in performance in corridor $(\boldsymbol{A})$ and staircase $(\boldsymbol{B}, \boldsymbol{C})$ tests. Performance in the corridor test was calculated by dividing the number of contralateral retrievals by the total number of retrievals from both sides. Performance in the staircase test was calculated as the number of retrieved or eaten pellets on the impaired side divided by the total number of pellets on both sides and expressed as percentage of performance at baseline. Data are means \pm SEMs; ${ }^{*} p<0.05$, repeated-measures ANOVA. D, Location and pattern of ischemic injury, mainly confined to the lateral and dorsolateral parts of striatum, shown by Neun staining in brain sections from strokesubjected mice, treated with vehicle or MC-21, at 18 weeks after insult. Insets are enlargements from respective coronal sections. Scale bar, $1 \mathrm{~mm}$. $\boldsymbol{E}$, Mean volume of ischemic lesion treated with vehicle $(n=9)$ or MC-21 $(n=10)$, at 18 weeks after insult. Data are means \pm SEMs; ${ }^{*} p<0,05$, unpaired $t$ test.

sult (Fig. 7B). In intact animals, $>70 \%$ of monocytes were Ly6C $\mathrm{C}^{\text {low }} / \mathrm{CX} 3 \mathrm{CR} 1^{\text {int }}$ and only $5 \%$ were $\mathrm{Ly} 6 \mathrm{C}^{\text {high }} / \mathrm{CX} 3 \mathrm{CR} 1^{\text {low }}$ (Fig. $7 B$ ). Most of the monocytes in the intact brain are those that have not been washed out from capillaries during the perfusion of animals before brain excision (Fig. 3C). At day 1 after stroke, $\sim 40 \%$ of the MDMs were Ly6C $\mathrm{C}^{\text {high }} / \mathrm{CX} 3 \mathrm{CR} 1^{\text {low }}$, reaching the peak at day $3(53 \%)$. Their percentage then gradually decreased to $18.3 \%$ at day 21 . At day 3 after stroke, the percentage of Ly6C ${ }^{\text {low } /}$ CX3CR $1{ }^{\text {int }}$ MDMs was $19 \%$, and their percentage increased at day $7(34.2 \%)$ and then remained stable at days 14 and $21(40.1$ and $38.7 \%$, respectively). Together, our data show that the relative ratio between the two subpopulations of MDMs was shifted toward the proinflammatory phenotype at day 3 and toward the anti-inflammatory phenotype thereafter (Fig. $7 B$ ).

We then asked whether the increase of the number of MDMs with the $\mathrm{Ly} 6 \mathrm{C}^{\text {low }} / \mathrm{CX} 3 \mathrm{CR} 1^{\text {int }}$ phenotype from day 3 to day 7 after stroke was accompanied by corresponding changes in antiinflammatory characteristics. The Ly6 $\mathrm{C}^{\text {high }} / \mathrm{CX} 3 \mathrm{CR} 1^{\text {low }}$ and Ly6 $\mathrm{C}^{\text {low }} / \mathrm{CX} 3 \mathrm{CR} 1^{\text {int }}$ populations were analyzed by flow cytometry for the expression of characteristic markers of anti-inflammatory activity, CD206, Dectin-1, and CD204. The percentage of cells expressing CD206 and Dectin-1 was increased within the Ly6C $\mathrm{C}^{\text {low }}$ CX3CR $1{ }^{\text {int }}$ but not within the Ly6C ${ }^{\text {high }} / \mathrm{CX} 3 \mathrm{CR} 1^{\text {low }}$ subpopulation (Fig. 7C). The percentage of cells immunoreactive for CD204 ${ }^{+}$, known as macrophage scavenger receptor 1 , did not change in either population (Fig. 7C).
We also analyzed the ratio between MDMs and microglia in chimeric animals at days 3 and 7 after stroke. At $3 \mathrm{~d}$, when the number of MDMs was at its maximum, they represented $61.6 \%$ of the whole $\mathrm{CD} 45^{+} / \mathrm{CD} 11 \mathrm{~b}{ }^{+}$cell population, whereas microglia constituted $24.6 \%$ (Fig. 7D). Conversely, at $7 \mathrm{~d}$ after stroke, microglia had become the dominant population, representing $66.9 \%$ and MDMs only $12.6 \%$. The phenotypic characterization of microglia based on flow cytometry analysis of Ly6C and CX3CR1 expression revealed (Fig. 7E) that, at both time points, these cells had predominantly proinflammatory activity (65.2 and $88.2 \%$ at 3 and $7 \mathrm{~d}$, respectively).

The immunological milieu is determined not only by MDMs and microglia but also by other cells producing proinflammatory and anti-inflammatory factors. Therefore, we assessed the overall changes in expression of several proinflammatory and antiinflammatory genes (Table 1 ) at 3, 7, and $14 \mathrm{~d}$ after stroke in the ipsilateral and contralateral hemispheres (Fig. 8A). Quantitative PCR revealed upregulation of only the gene encoding for the anti-inflammatory molecule $\mathrm{Ym} 1$ at $3 \mathrm{~d}$ after stroke. At $7 \mathrm{~d}$, the expression of genes encoding for the anti-inflammatory-associated molecules TGF $\beta 1$, Ym1, CXCL13, CCL22, and CD163 was increased, along with increased expression of the proinflammationassociated genes IL-6, TNF $\alpha$, IL- $1 \beta$, and NOS2. However, at $14 \mathrm{~d}$, only two anti-inflammatory genes, TGF $\beta 1$ and VCAM1, were upregulated. No significant changes in the expression of the other ex- 

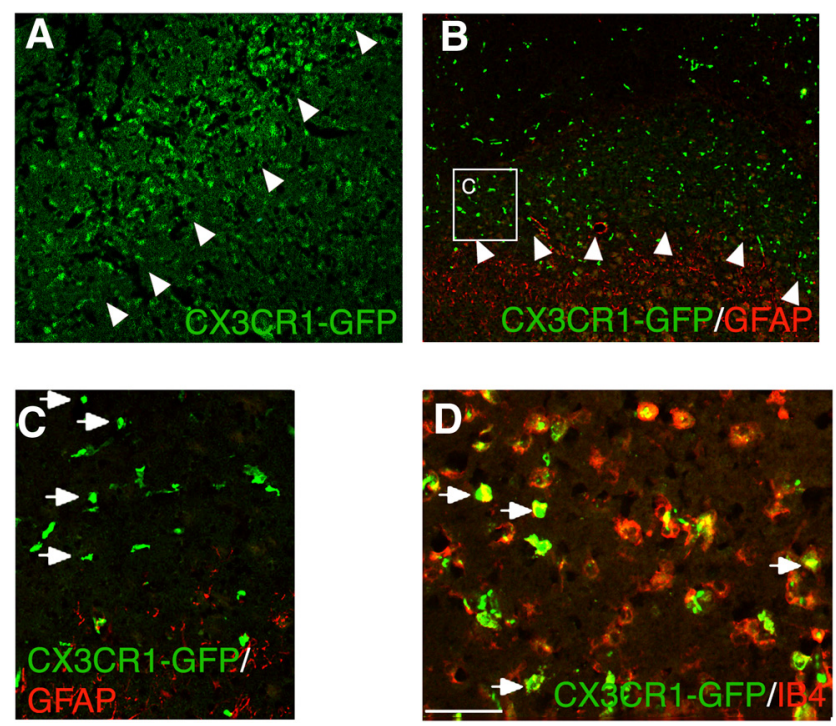

Figure 6. $\quad \mathrm{CX} 3 \mathrm{CR} 1-\mathrm{GFP}{ }^{+} \mathrm{MDM}$ infiltrate the lesion site of chimeric mice subjected to ischemic stroke. $\boldsymbol{A}, \boldsymbol{B}$, Fluorescence microscopic images of mouse brain coronal sections showing distribution of $\mathrm{GFP}^{+} \mathrm{MDMs}$ and $\mathrm{GFAP}{ }^{+}$astrocytes within and outside the ischemically injured tissue, respectively. Arrowheads depict the lesion border. C, Enlargement of inset depicted in $\boldsymbol{B}$. Arrows point to individual GFP ${ }^{+}$MDMs. $\boldsymbol{D}$, Fluorescence microscopic image showing doubleimmunostaining of GFP ${ }^{+}$MDMs (green) with the activation marker IB4 (red). The majority of MDMs are immunopositive for IB4 (arrows). Scale bar (in D): $\boldsymbol{A}, \boldsymbol{B}, 250 \mu \mathrm{m} ; \boldsymbol{C}, 100 \mu \mathrm{m} ; \boldsymbol{D}, 50$ $\mu \mathrm{m}$.

amined proinflammatory and anti-inflammatory genes were detected (Table 1).

Changes in the expression of some proinflammatory and antiinflammatory proteins in MDMs were verified by immunocytochemistry in the CX3CR1-GFP chimeric mice (Fig. 8D). We used three antibodies, against IL-6, TGF $\beta$, and BDNF, respectively, which gave rise to specific labeling. Confocal microscopy revealed that, at $7 \mathrm{~d}$ after the insult, virtually all $\mathrm{IL}_{-} 6^{+}$cells were $\mathrm{GFP}{ }^{+}$ MDMs (Fig. 8D). Of all TGF $\beta^{+}$and $\mathrm{BDNF}^{+}$cells, $88.1 \pm 34.3$ and $82.3 \pm 22.2 \%$, respectively, were also $\mathrm{GFP}^{+}$at $7 \mathrm{~d}$ after stroke. These findings indicate that MDMs were the main source of these growth factors, although other cells such as neurons and astrocytes may also contribute. We estimated that $90.7 \pm 5.6$ and $87.5 \pm 5.3 \%$ of MDMs were IL- $6^{+}$at 3 and $7 \mathrm{~d}$ after stroke, respectively. At $3 \mathrm{~d}$ after stroke, $85.8 \pm 6.8$ and $85.7 \pm 9.7 \%$ of MDMs expressed TGF $\beta$ and BDNF, respectively, which seemed to increase slightly (to $98.5 \pm 1.3$ and $98.8 \pm 0.3 \%$, respectively) at $7 \mathrm{~d}$.

Depletion of circulating monocytes preferentially reduces anti-inflammatory factor expression in stroke-injured brain We next examined how the depletion of infiltrating MDMs affected the brain tissue milieu. For this purpose, animals subjected to stroke and MC-21 or vehicle treatment were killed at 7 and $14 \mathrm{~d}$ after the insult, and the ipsilateral and contralateral hemispheres were processed for quantitative PCR analysis of genes with proinflammatory or anti-inflammatory function. At $7 \mathrm{~d}$ after stroke, when circulating monocytes were completely depleted, we detected a dramatic decrease only in gene expression of the cytokine Ym1 (associated with anti-inflammatory activity; Fig. 9A). Other tested markers were not altered. However, at $14 \mathrm{~d}$ after stroke, when the number of circulating monocytes was fully restored, we found significant decreases in gene expression levels of several anti-inflammatory molecules, such as TGF $\beta 1$, TGF $\beta 2$, and
CD163, in the MC-21-treated group (Fig. 9A). At this time point, decreased gene expression for NOS2 was the only significant difference in markers of proinflammatory activity in MC-21-treated compared with vehicle-injected animals. Counting of the number of activated microglia/macrophages showed that treatment with MC-21 significantly decreased the percentage of $\mathrm{ED}^{+}$/ $\mathrm{Iba}^{+}$cells in the lesioned striatum at $14 \mathrm{~d}$ after the insult (Fig. 9B). These findings support our contention that the contribution of the infiltrating MDMs to long-term functional recovery could be attributed to their anti-inflammatory activity.

\section{Discussion}

It is well established that ischemic stroke leads to brain inflammation, involving activated astrocytes and microglia, as well as infiltration of myeloid cells and lymphocytes into the ischemic brain hemisphere (Kochanek and Hallenbeck, 1992; Tomita and Fukuuchi, 1996; Stoll et al., 1998; Campanella et al., 2002; Stevens et al., 2002; Danton and Dietrich, 2003; Gelderblom et al., 2009; Denes et al., 2010; Jin et al., 2010; Miró-Mur et al., 2016). Although excitotoxicity causes neuronal death shortly after the onset of the ischemic insult, the inflammatory reaction is part of the repair mechanism that takes days to reach its peak and, therefore, gives a reasonable window for therapeutic interventions (Dirnagl et al., 1999; Shechter and Schwartz, 2013). Here we demonstrate, for the first time, that the monocytes recruited from the blood to the stroke-injured brain are importantly involved in the longterm spontaneous functional recovery. At the lesion site, MDMs with two distinct phenotypes were found: first, proinflammatory and, subsequently, anti-inflammatory. Depletion of circulating monocytes during the first week after stroke and the resulting decrease of MDMs at the site of the injury caused impaired recovery of sensorimotor deficits in the chronic phase after MCAO.

In agreement with our findings, several recent studies have demonstrated that maximum infiltration of blood-borne monocytes in the ischemic brain tissue occurs within 2 and $3 \mathrm{~d}$ after stroke (Gelderblom et al., 2009; Gliem et al., 2012; Hammond et al., 2014; Michaud et al., 2014; Ritzel et al., 2015; Miró-Mur et al., 2016). However, those studies were focusing only on the early events (mostly up to $7 \mathrm{~d}$ ) after stroke and did not explore the possible contribution of the infiltrating monocytes to long-term functional recovery. Recently, it was reported that so-called patrolling Ly $6 \mathrm{C}^{\text {low }}$ monocytes do not influence the progression and recovery of ischemic stroke (Michaud et al., 2014). In contrast, several studies indicated a role for infiltrating Ly6 $\mathrm{C}^{\text {high }}$ monocytes in the acute phase after the insult. Gliem et al. (2012) found that depletion of circulating monocytes during the first days after MCAO or photothrombotic stroke using chlodronate-filled liposomes or diphtheria toxin injection in mice caused hemorrhagic transformation of the infarct without affecting lesion volume. There was also lack of improvement in the rotarod test during the first $5 \mathrm{~d}$ after ischemia. These findings indicated that MDMs are involved in maintaining the neurovascular unit after stroke. Chu et al. (2015) injected a selective CCR2 receptor antagonist $1 \mathrm{~h}$ before and 2 and $6 \mathrm{~h}$ after MCAO in mice to prevent the recruitment of Ly6C ${ }^{\text {high }}$ monocytes to the brain. At $24 \mathrm{~h}$, they found more extensive lesion and worse functional outcome as evidenced by higher neurological deficit score and shorter hanging wire latency to fall. These findings indicated an acute protective effect exerted by the recruited monocytes. In line with our findings, this study also demonstrated that ablation of infiltrating monocytes leads to specific decrease of cells with antiinflammatory characteristic activity, such as Ym1, with no effect on expression of proinflammatory characteristic activities, such 
A
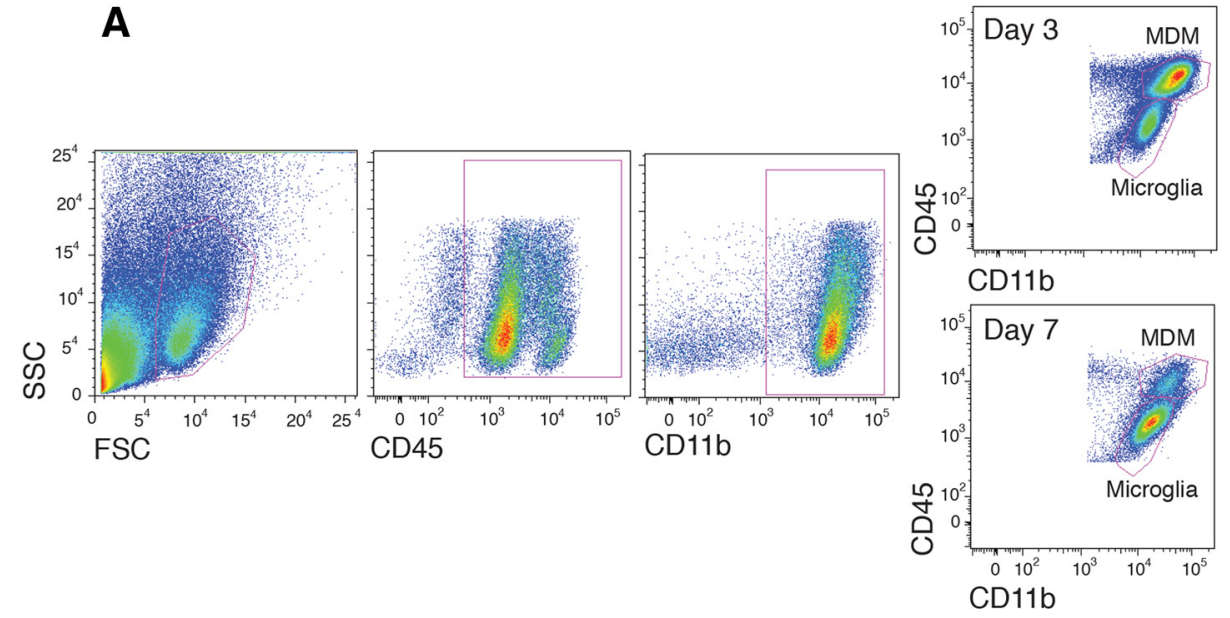

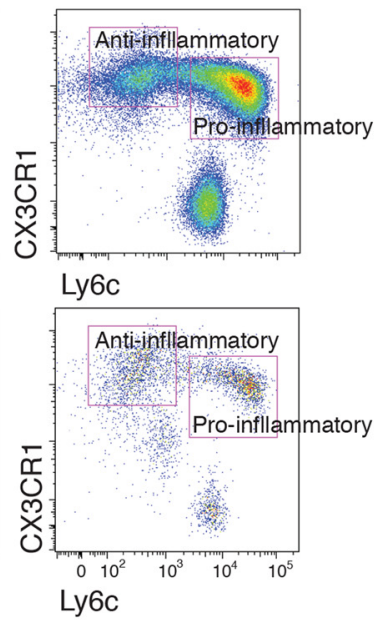

B

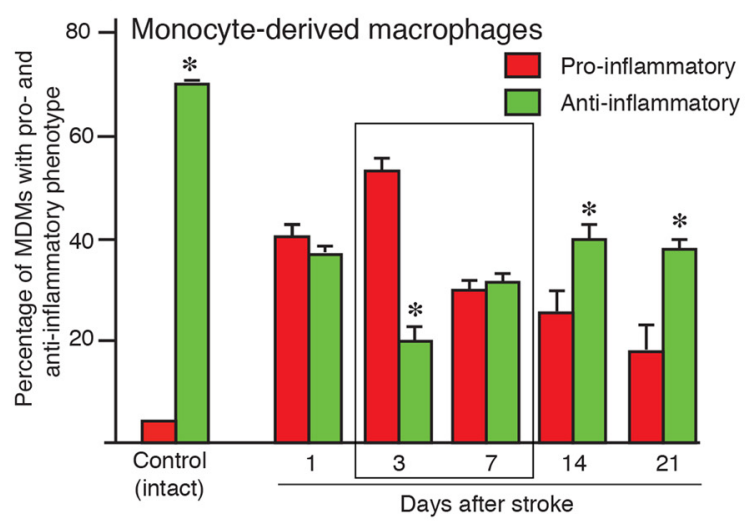

D

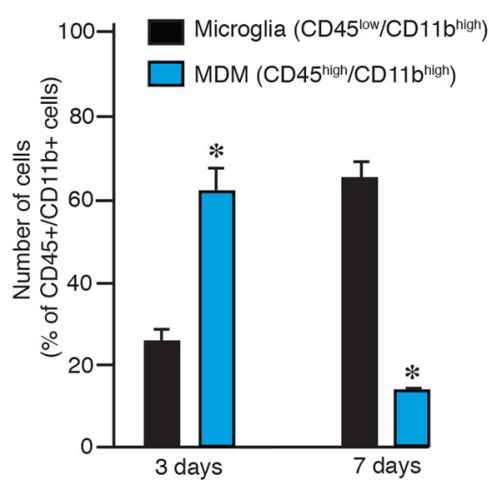

C

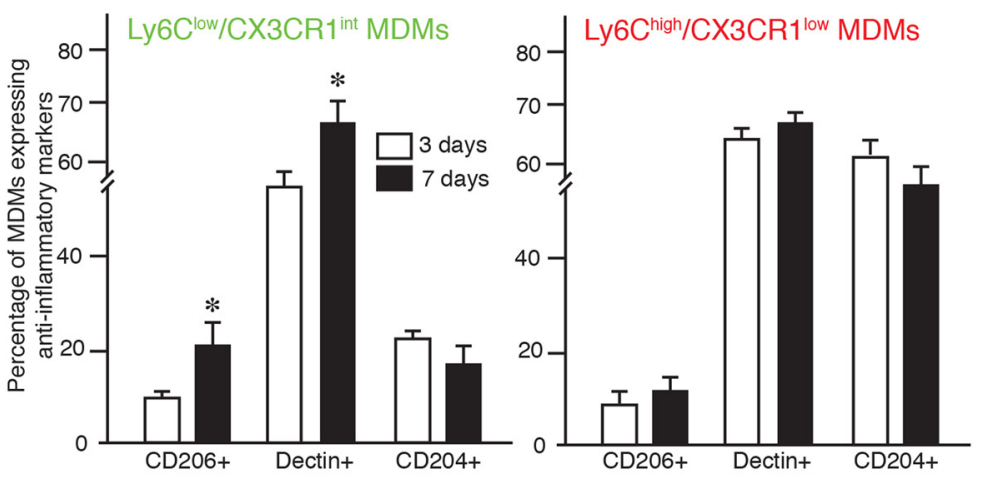

E

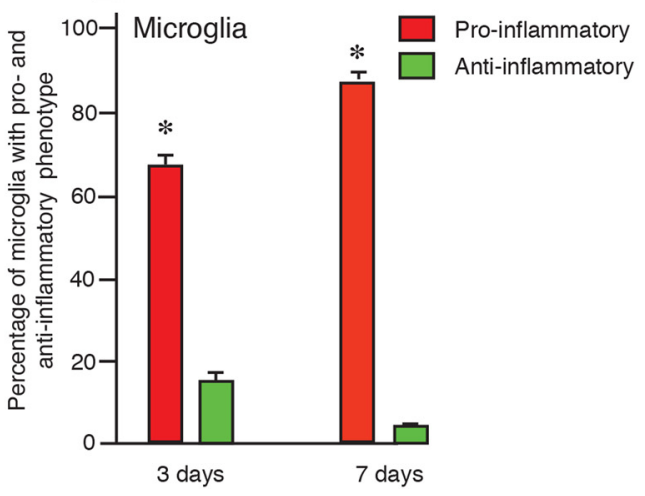

Figure 7. MDMs switch from a proinflammatory to anti-inflammatory phenotype during the first weeks after stroke. $\boldsymbol{A}$, Flow cytometry analysis of the brain hemisphere ipsilateral to the lesion in mice subjected to stroke and killed 3 and $7 \mathrm{~d}$ thereafter. CD45/CD11b immunoreactivity is used to distinguish MDMs and microglia and CX3CR1/Ly6C to define proinflammatory and antiinflammatory phenotype of MDMs. $\boldsymbol{B}$, Changes as a function of time in percentage of MDMs with a proinflammatory and anti-inflammatory phenotype defined by flow cytometry analysis in the ischemically injured brains; intact hemispheres were used as controls. $C$, Estimation of the percentage of $C D 204^{+}, C D_{206}{ }^{+}$, and Declin ${ }^{+}$cells within the MDM population in the injured hemisphere of mice subjected to stroke and killed 3 and $7 \mathrm{~d}$ thereafter. D, Estimation of the percentage of microglia and MDMs in injured hemisphere of mice subjected to stroke and killed 3 and $7 \mathrm{~d}$ thereafter. $\boldsymbol{E}$, Estimation of the percentage of microglia with a proinflammatory and anti-inflammatory phenotype in the injured hemisphere of mice subjected to stroke and killed 3 and $7 \mathrm{~d}$ thereafter. SSC, Side scatter; FSC, forward scatter. Number of animals: Control, $n=4$; Day $1, n=3 ;$ Day $3, n=12 ;$ Day $7, n=7 ;$ Day $14, n=5 ;$ and Day $21, n=6$. Data are means \pm SEMs; ${ }^{*} p<0,05$, unpaired $t$ test between the proinflammatory and anti-inflammatory phenotype $(\boldsymbol{B}, \boldsymbol{E}), 3$ and $7 \mathrm{~d}(\boldsymbol{C})$, and microglia and MDMs (D).

as TNF, IL-6, and IL- $1 \beta$. In agreement, monocyte ablation caused twofold greater proportion of $\mathrm{F} 4 / 80^{+}$macrophages that were positive to 3-nitrotyrosine, a feature of a proinflammatory activity (Chu et al., 2015).

In contrast, in another type of stroke, intracerebral hemorrhage, Ly $6 C^{\text {high }}$ monocytes were recruited to the injured brain, produced TNF, and contributed to the early functional impairment (Hammond et al., 2014). Ccr2 $2^{-/-}$mice and bone-marrow chimeras, which had fewer monocytes in the brain, displayed less severe forelimb weakness during the first 1-3 d. A similar effect was observed after treatment with the MC-21 antibody used here $1 \mathrm{~d}$ before and immediately after the hemorrhage. In our experi- 

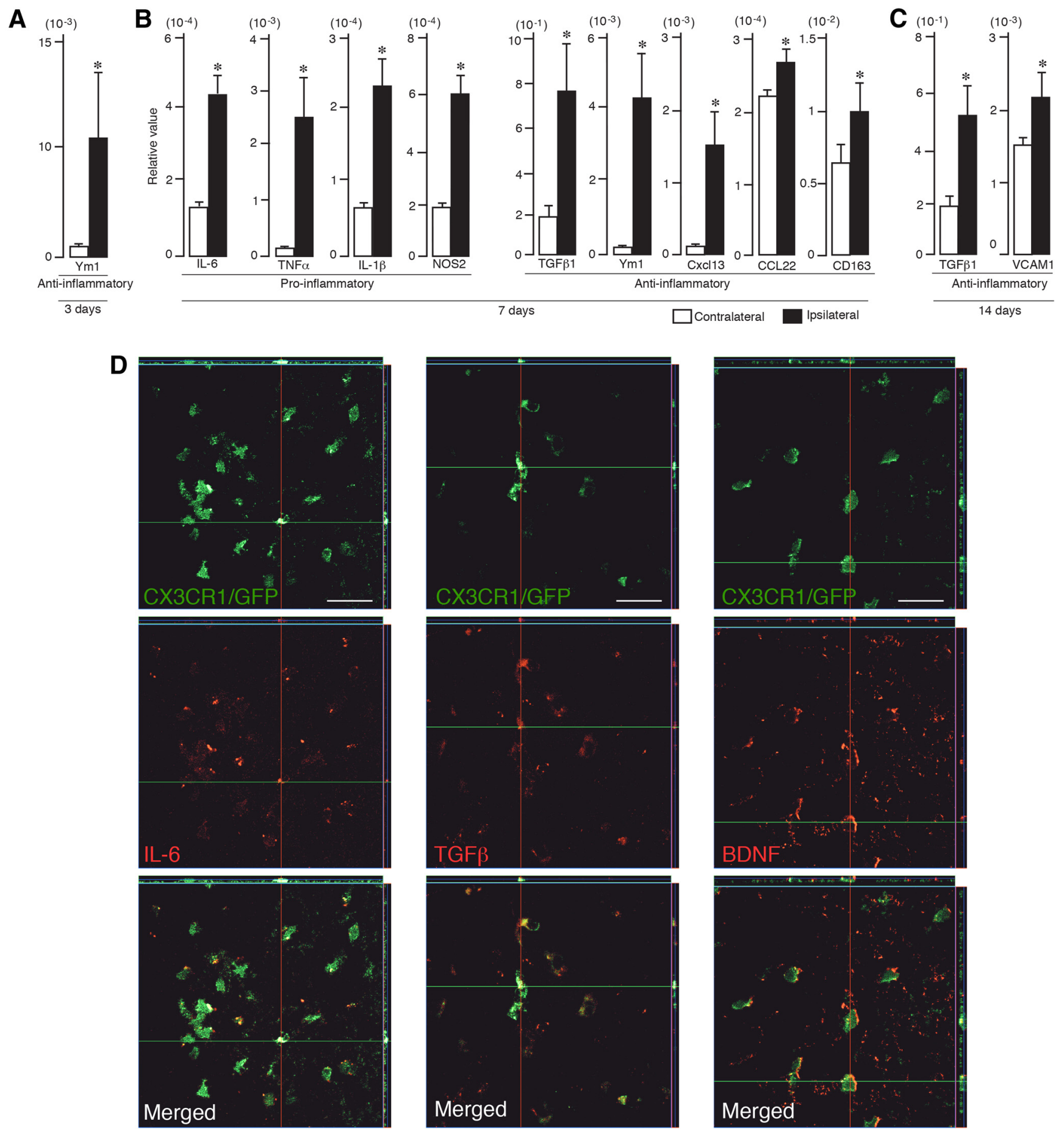

Figure 8. Proinflammatory and anti-inflammatory factors are expressed in the stroke-injured hemisphere. $\boldsymbol{A}-\boldsymbol{C}$, Quantitative PCR shows increased expression in the injured (ipsilateral) hemisphere of anti-inflammatory factor (Ym1) at $3 \mathrm{~d}(\boldsymbol{A})$, proinflammatory (IL-6, TNF $\alpha$, IL-1 $\beta$, NOS2) and anti-inflammatory (TGF $\beta 1$, Ym1, CXCL113, CCL22, CD163) factors at $7 \mathrm{~d}$ (B), and anti-inflammatory factors (TGF $\beta 1, V C A M 1)$ at $14 \mathrm{~d}(\boldsymbol{C})$ after stroke $(n=7)$. Data are means \pm SEMs; ${ }^{*} p<0.05$, unpaired $t$ test. $\boldsymbol{D}$, Fluorescence microscopic images of CXCR3-GFP ${ }^{+}$chimeric mouse brain coronal sections showing double-immunostaining of MDMs (green) and IL-6, TGF $\beta$, and BDNF (all red) at 3 and $7 \mathrm{~d}$ after stroke. Note the decreased immunoreactivity for IL-6 and increased staining for TGF $\beta$ and BDNF at $7 \mathrm{~d}$ compared with $3 \mathrm{~d}$. Scale bar, $150 \mu \mathrm{m}$.

ments, the ischemic lesion was relatively small $\left(\sim 5.6 \mathrm{~mm}^{3}\right)$ and mostly confined to the dorsolateral part of the striatum. Whether the long-term beneficial effects of monocytes on impaired sensorimotor functions shown in animals with moderate striatal lesion would also occur in animals with larger striatal or combined striatocortical damage requires additional investigation. Moreover, the origin, severity, and the type of stroke could affect the extent and dynamics of the inflammatory response (Zhou et al.,
2013). Together, these findings raise the possibility that the effect of the infiltrating monocytes and the resulting functional outcome depend on the type and severity of brain injury and the stage at which recruitment is blocked and spontaneous recovery is assessed.

We found strong upregulation of the expression of genes encoding for both proinflammatory (IL-6, TNF $\alpha$, IL- $1 \beta$, and NOS2) and anti-inflammatory (Ym1, TGF $\beta$, CXCL13, CCL22, 
A

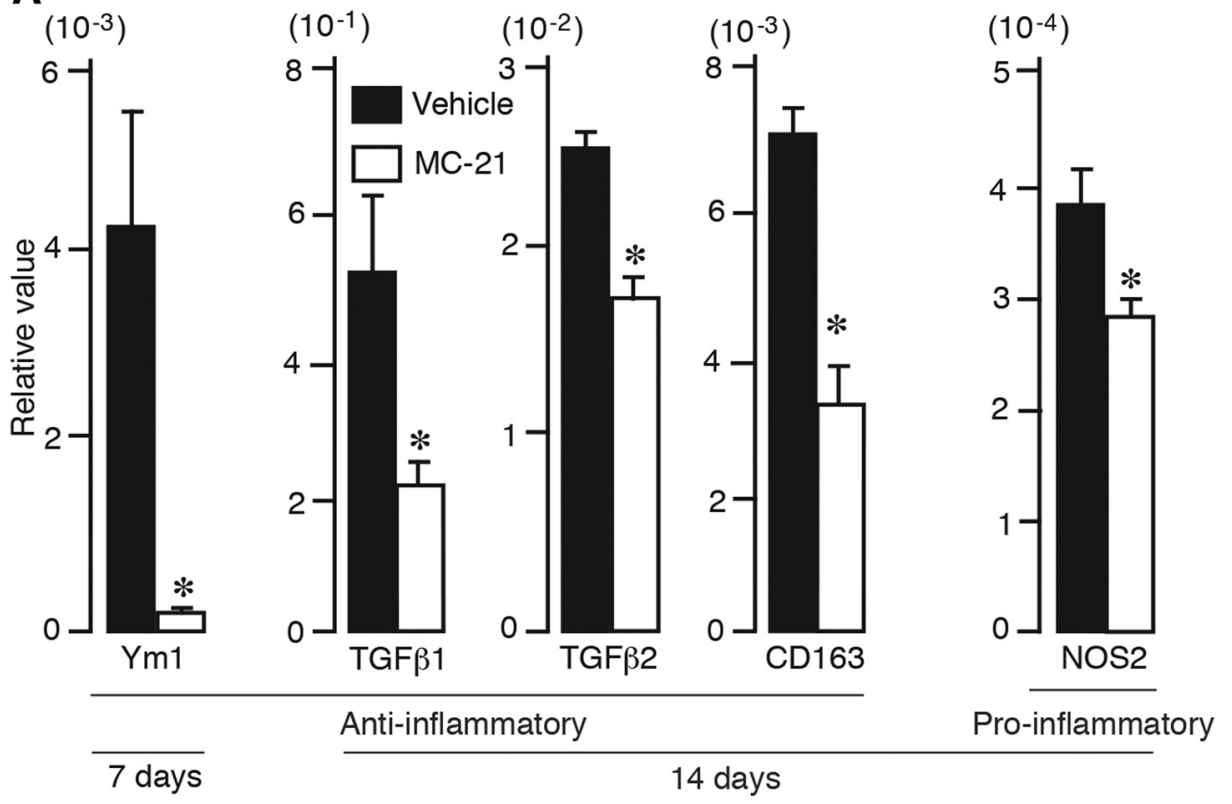

B

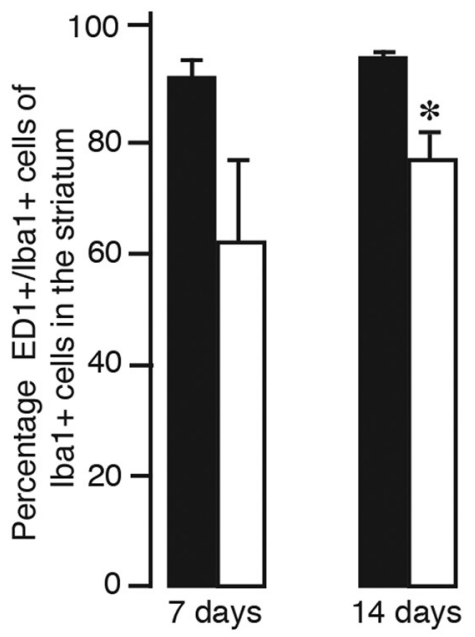

Figure 9. Depletion of circulating monocytes preferentially reduces anti-inflammatory factor expression in stroke-injured brain. $\boldsymbol{A}, \mathbf{Q}$ Quantitative $P C R$ showing decreased expression of antiinflammatory (Ym1, TGF $\beta 1$, TGF $\beta 2$, CD163) and proinflammatory (NOS2) factors in the injured hemisphere of animals treated with vehicle or MC-21 and killed at 3 (vehicle, $n=5$; MC-21, $n=5$ ), 7 (vehicle, $n=6$; MC-21, $n=5$ ), or 14 (vehicle, $n=5 ; M C-21, n=5$ ) days after stroke. Data are means \pm SEMs; ${ }^{*} p<0.05$, unpaired $t$ test. $\boldsymbol{B}$, Number of ED ${ }^{+}$cells expressed as percentage of total number of $\mathrm{Iba}^{+}{ }^{+}$cells in the injured hemisphere of animals treated with vehicle or MC-21 and killed at 7 or $14 \mathrm{~d}$ after stroke. Data are means \pm SEMs; ${ }^{*} p<0.05$, unpaired $t$ test.

and CD163) factors at 1 week after stroke. Similarly, $\mathrm{Hu}$ et al. (2012) showed that expression of both proinflammatory and anti-inflammatory makers in the ischemic hemisphere peaks at $\sim 5 \mathrm{~d}$ after stroke. Because we analyzed whole-hemisphere homogenates, the cellular origins could not be determined. However, MDMs and microglia most likely constituted the main source of the observed gene expression, although minor contributions from neurons and astrocytes cannot be excluded. At $7 \mathrm{~d}$ after stroke, the number of activated microglia was more than fourfold higher than the number of MDMs, and $~ 80 \%$ of microglia exhibited proinflammatory activity. At the same time point, the number of MDMs with proinflammatory and antiinflammatory profiles were similar. These findings suggest that the increased expression of genes encoding for proinflammatory activities at 1 week after stroke can be attributed mostly to microglia, whereas the changes in anti-inflammatory gene expression is mainly in MDMs. In accordance, depletion of circulating monocytes during the first week after stroke lead to reduced expression predominantly of anti-inflammatory genes (Ym1, TGF $\beta$, and CD163). Interestingly, these three genes have been upregulated in response to stroke at days 3 and 7 (Ym1), only at day 7 (CD163), or at days 7 and 14 (TGF $\beta$ ).

The ablation of circulating monocytes in the early phase after stroke apparently did not influence the size of the lesion at 18 weeks after insult. Thus, it is very likely, based on the MC-21 monocyte-depletion experiment, that the effect of the MDMs with a bias toward anti-inflammatory activity on recovery is not mediated through neuroprotection but by creating an immunological microenvironment that supports tissue remodeling. In agreement with our findings, poststroke chronic treatment with the adenosine $5^{\prime}$-monophosphate-activated protein kinase activator metformin promoted functional recovery and tissue repair via an anti-inflammatory-polarization mechanism after experimental stroke without affecting ischemic lesion volume (Jin et al., 2014). This treatment resulted in fewer cells immunopositive to anti-inflammatory markers, such as CD32 and IL-1 $\beta$, and increased numbers of cells expressing anti-inflammatory markers, such as CD206, Arginase 1, and IL-10. Metformin treatment also stimulated angiogenesis and induced increased numbers of doublecortin ${ }^{+}$neuroblasts in the subventricular zone.

Among the MDM-related anti-inflammatory factors contributing to long-term spontaneous recovery after stroke is TGF $\beta 1$, which was reported to be involved in the action of MDMs during the first days after stroke for maintaining the integrity of the neurovascular unit (Gliem et al., 2012). Based on our findings, it seems possible that TGF $\beta 1$ could play an important role also in mediating the long-term effects of MDMs on recovery. Other studies have demonstrated increased expression of TGF $\beta$ (Lehrmann et al., 1998; Martinez et al., 2001; Doyle et al., 2010; Pál et al., 2012) and its receptor (Pál et al., 2014) after stroke, mostly in macrophages (Lehrmann et al., 1998; Martinez et al., 2001; Doyle et al., 2010). TGF $\beta$ has been shown to suppress excessive neuroinflammation during the subacute phase after brain ischemia, as evidenced by decreased expression of the proinflammatory microglia/macrophage markers CD68 and iNOS (Cekanaviciute et al., 2014), and is also able to directly inhibit LPSmediated activation of microglia (Kim et al., 2004; Le et al., 2004). Zhou et al. (2012) recently demonstrated that TGF $\beta$ enhances IL-4-induced alternative activation of microglia by strongly increasing the expression of Ym1. TGF $\beta$ also contributes to poststroke neurogenesis from the subventricular zone and functional recovery in neurological tests (Ma et al., 2008). Together, our findings provide strong evidence that the decreased TGF $\beta$ expression in the ischemic brain after MC-21 treatment could contribute to the impaired functional recovery.

Another anti-inflammatory factor, which was downregulated after monocyte depletion, is CD163, a phagocytic marker functioning as a membrane-bound scavenger receptor for clearing the extracellular haptoglobin-hemoglobin complex (Schaer et al., 2007). It has immunoregulatory function and is associated with 
resolution of inflammation, which is important for functional recovery after stroke (Clark et al., 1993). The mechanisms of poststroke resolution are not fully understood (Shichita et al., 2014), but our findings raise the possibility that alterations in the resolution of inflammation, secondary to decreased CD163 level, could be involved in the impaired recovery after stroke.

Finally, the MC-21 treatment caused decreased expression of Ym1, an established marker for alternative activation of microglia/macrophages (Chang et al., 2001; Nio et al., 2004). Ym1 is a heparin/heparin sulfate-binding lectin that is expressed transiently during inflammation (Hung et al., 2002). Although its precise functions remain elusive, $\mathrm{Ym} 1$ has been suggested to be involved in tissue remodeling and regulation of inflammation (Giannetti et al., 2004). If this is the case, Ym1 may contribute to poststroke functional recovery.

Our findings reveal a critical role of the MDMs infiltrating to the injured brain early after the insult in the long-term functional recovery after stroke. The transition of MDMs from proinflammatory to anti-inflammatory bias during the first 3 weeks after ischemia leads to modulation of the inflammatory tissue environment and is associated with improved functional outcome. This new insight could have important therapeutic implications by raising the possibility that inadequate recruitment of MDMs after stroke underlies the incomplete functional recovery seen in both animals and patients. Future studies will show whether this physiological repair mechanism can be potentiated by increasing the homing of macrophages, derived from endogenous or grafted monocytes in the peripheral blood, to the ischemically injured brain.

\section{References}

Andsberg G, Kokaia Z, Lindvall O (2001) Upregulation of p75 neurotrophin receptor after stroke in mice does not contribute to differential vulnerability of striatal neurons. Exp Neurol 169:351-363. CrossRef Medline

Baird AL, Meldrum A, Dunnett SB (2001) The staircase test of skilled reaching in mice. Brain Res Bull 54:243-250. CrossRef Medline

Benakis C, Garcia-Bonilla L, Iadecola C, Anrather J (2015) The role of microglia and myeloid immune cells in acute cerebral ischemia. Front Cell Neurosci 8:461. CrossRef Medline

Bose S, Cho J (2013) Role of chemokine CCL2 and its receptor CCR2 in neurodegenerative diseases. Arch Pharm Res 36:1039-1050. CrossRef Medline

Campanella M, Sciorati C, Tarozzo G, Beltramo M (2002) Flow cytometric analysis of inflammatory cells in ischemic rat brain. Stroke 33:586-592. CrossRef Medline

Cekanaviciute E, Fathali N, Doyle KP, Williams AM, Han J, Buckwalter MS (2014) Astrocytic transforming growth factor-beta signaling reduces subacute neuroinflammation after stroke in mice. Glia 62:1227-1240. CrossRef Medline

Chang NC, Hung SI, Hwa KY, Kato I, Chen JE, Liu CH, Chang AC (2001) A macrophage protein, $\mathrm{Yml}$, transiently expressed during inflammation is a novel mammalian lectin. J Biol Chem 276:17497-17506. CrossRef Medline

Chu HX, Kim HA, Lee S, Moore JP, Chan CT, Vinh A, Gelderblom M, Arumugam TV, Broughton BR, Drummond GR, Sobey CG (2014) Immune cell infiltration in malignant middle cerebral artery infarction: comparison with transient cerebral ischemia. J Cereb Blood Flow Metab 34:450-459. CrossRef Medline

Chu HX, Broughton BR, Kim HA, Lee S, Drummond GR, Sobey CG (2015) Evidence that Ly6C(hi) monocytes are protective in acute ischemic stroke by promoting M2 macrophage polarization. Stroke 46:1929-1937. CrossRef Medline

Clark RK, Lee EV, Fish CJ, White RF, Price WJ, Jonak ZL, Feuerstein GZ, Barone FC (1993) Development of tissue damage, inflammation and resolution following stroke: an immunohistochemical and quantitative planimetric study. Brain Res Bull 31:565-572. CrossRef Medline

Danton GH, Dietrich WD (2003) Inflammatory mechanisms after ischemia and stroke. J Neuropathol Exp Neurol 62:127-136. CrossRef Medline

Denes A, Thornton P, Rothwell NJ, Allan SM (2010) Inflammation and brain injury: acute cerebral ischaemia, peripheral and central inflammation. Brain Behav Immun 24:708-723. CrossRef Medline

Dirnagl U, Iadecola C, Moskowitz MA (1999) Pathobiology of ischaemic stroke: an integrated view. Trends Neurosci 22:391-397. CrossRef Medline

Dowd E, Monville C, Torres EM, Dunnett SB (2005) The Corridor Task: a simple test of lateralised response selection sensitive to unilateral dopamine deafferentation and graft-derived dopamine replacement in the striatum. Brain Res Bull 68:24-30. CrossRef Medline

Doyle KP, Cekanaviciute E, Mamer LE, Buckwalter MS (2010) TGFbeta signaling in the brain increases with aging and signals to astrocytes and innate immune cells in the weeks after stroke. J Neuroinflammation 7:62. CrossRef Medline

Faustino JV, Wang X, Johnson CE, Klibanov A, Derugin N, Wendland MF, Vexler ZS (2011) Microglial cells contribute to endogenous brain defenses after acute neonatal focal stroke. J Neurosci 31:12992-13001. CrossRef Medline

Franco R, Fernández-Suárez D (2015) Alternatively activated microglia and macrophages in the central nervous system. Prog Neurobiol 131:65-86. CrossRef Medline

Gadani SP, Walsh JT, Lukens JR, Kipnis J (2015) Dealing with danger in the CNS: the response of the immune system to injury. Neuron 87:47-62. CrossRef Medline

Gelderblom M, Leypoldt F, Steinbach K, Behrens D, Choe CU, Siler DA, Arumugam TV, Orthey E, Gerloff C, Tolosa E, Magnus T (2009) Temporal and spatial dynamics of cerebral immune cell accumulation in stroke. Stroke 40:1849-1857. CrossRef Medline

Giannetti N, Moyse E, Ducray A, Bondier JR, Jourdan F, Propper A, Kastner A (2004) Accumulation of $Y m 1 / 2$ protein in the mouse olfactory epithelium during regeneration and aging. Neuroscience 123:907-917. CrossRef Medline

Gliem M, Mausberg AK, Lee JI, Simiantonakis I, van Rooijen N, Hartung HP, Jander S (2012) Macrophages prevent hemorrhagic infarct transformation in murine stroke models. Ann Neurol 71:743-752. CrossRef Medline

Gordon S, Taylor PR (2005) Monocyte and macrophage heterogeneity. Nat Rev Immunol 5:953-964. CrossRef Medline

Grealish S, Mattsson B, Draxler P, Björklund A (2010) Characterisation of behavioural and neurodegenerative changes induced by intranigral 6-hydroxydopamine lesions in a mouse model of Parkinson's disease. Eur J Neurosci 31:2266-2278. CrossRef Medline

Hammond MD, Taylor RA, Mullen MT, Ai Y, Aguila HL, Mack M, Kasner SE, McCullough LD, Sansing LH (2014) CCR2+ Ly6C(hi) inflammatory monocyte recruitment exacerbates acute disability following intracerebral hemorrhage. J Neurosci 34:3901-3909. CrossRef Medline

Hara H, Huang PL, Panahian N, Fishman MC, Moskowitz MA (1996) Reduced brain edema and infarction volume in mice lacking the neuronal isoform of nitric oxide synthase after transient MCA occlusion. J Cereb Blood Flow Metab 16:605-611. CrossRef Medline

Hu X, Li P, Guo Y, Wang H, Leak RK, Chen S, Gao Y, Chen J (2012) Microglia/macrophage polarization dynamics reveal novel mechanism of injury expansion after focal cerebral ischemia. Stroke 43:3063-3070. CrossRef Medline

Hu X, Leak RK, Shi Y, Suenaga J, Gao Y, Zheng P, Chen J (2015) Microglial and macrophage polarization-new prospects for brain repair. Nat Rev Neurol 11:56-64. CrossRef Medline

Hung SI, Chang AC, Kato I, Chang NC (2002) Transient expression of Ym1, a heparin-binding lectin, during developmental hematopoiesis and inflammation. J Leukoc Biol 72:72-82. Medline

Jin Q, Cheng J, Liu Y, Wu J, Wang X, Wei S, Zhou X, Qin Z, Jia J, Zhen X (2014) Improvement of functional recovery by chronic metformin treatment is associated with enhanced alternative activation of microglia/macrophages and increased angiogenesis and neurogenesis following experimental stroke. Brain Behav Immun 40:131-142. CrossRef Medline

Jin R, Yang G, Li G (2010) Inflammatory mechanisms in ischemic stroke: role of inflammatory cells. J Leukoc Biol 87:779-789. CrossRef Medline

Jung S, Aliberti J, Graemmel P, Sunshine MJ, Kreutzberg GW, Sher A, Littman DR (2000) Analysis of fractalkine receptor CX(3)CR1 function by targeted deletion and green fluorescent protein reporter gene insertion. Mol Cell Biol 20:4106-4114. CrossRef Medline

Kawamoto JC, Barrett JN (1986) Cryopreservation of primary neurons for tissue culture. Brain Res 384:84-93. CrossRef Medline

Kim WK, Hwang SY, Oh ES, Piao HZ, Kim KW, Han IO (2004) TGF-betal represses activation and resultant death of microglia via inhibition of 
phosphatidylinositol 3-kinase activity. J Immunol 172:7015-7023. CrossRef Medline

Kochanek PM, Hallenbeck JM (1992) Polymorphonuclear leukocytes and monocytes/macrophages in the pathogenesis of cerebral ischemia and stroke. Stroke 23:1367-1379. CrossRef Medline

Ksander BR, Rubsamen PE, Olsen KR, Cousins SW, Streilein JW (1991) Studies of tumor-infiltrating lymphocytes from a human choroidal melanoma. Invest Ophthalmol Visual Sci 32:3198-3208. Medline

Le Y, Iribarren P, Gong W, Cui Y, Zhang X, Wang JM (2004) TGF-beta1 disrupts endotoxin signaling in microglial cells through Smad3 and MAPK pathways. J Immunol 173:962-968. CrossRef Medline

Lehrmann E, Kiefer R, Christensen T, Toyka KV, Zimmer J, Diemer NH, Hartung HP, Finsen B (1998) Microglia and macrophages are major sources of locally produced transforming growth factor-betal after transient middle cerebral artery occlusion in rats. Glia 24:437-448. CrossRef Medline

London A, Itskovich E, Benhar I, Kalchenko V, Mack M, Jung S, Schwartz M (2011) Neuroprotection and progenitor cell renewal in the injured adult murine retina requires healing monocyte-derived macrophages. J Exp Med 208:23-39. CrossRef Medline

Ma M, Ma Y, Yi X, Guo R, Zhu W, Fan X, Xu G, Frey WH 2nd, Liu X (2008) Intranasal delivery of transforming growth factor-betal in mice after stroke reduces infarct volume and increases neurogenesis in the subventricular zone. BMC Neurosci 9:117. CrossRef Medline

Mack M, Cihak J, Simonis C, Luckow B, Proudfoot AE, Plachý J, Brühl H, Frink M, Anders HJ, Vielhauer V, Pfirstinger J, Stangassinger M, Schlöndorff D (2001) Expression and characterization of the chemokine receptors CCR2 and CCR5 in mice. J Immunol 166:4697-4704. CrossRef Medline

Martinez G, Di Giacomo C, Sorrenti V, Carnazza ML, Ragusa N, Barcellona ML, Vanella A (2001) Fibroblast growth factor-2 and transforming growth factor-betal immunostaining in rat brain after cerebral postischemic reperfusion. J Neurosci Res 63:136-142. CrossRef Medline

Michaud JP, Pimentel-Coelho PM, Tremblay Y, Rivest S (2014) The impact of Ly6Clow monocytes after cerebral hypoxia-ischemia in adult mice. J Cereb Blood Flow Metab 34:e1-e9. CrossRef Medline

Mildner A, Schmidt H, Nitsche M, Merkler D, Hanisch UK, Mack M, Heikenwalder M, Brück W, Priller J, Prinz M (2007) Microglia in the adult brain arise from Ly-6ChiCCR2+ monocytes only under defined host conditions. Nat Neurosci 10:1544-1553. CrossRef Medline

Miró-Mur F, Pérez-de-Puig I, Ferrer-Ferrer M, Urra X, Justicia C, Chamorro A, Planas AM (2016) Immature monocytes recruited to the ischemic mouse brain differentiate into macrophages with features of alternative activation. Brain Behav Immun 53:18-33. Medline

Mitchell AJ, Roediger B, Weninger W (2014) Monocyte homeostasis and the plasticity of inflammatory monocytes. Cell Immunol 291:22-31. CrossRef Medline

Montoya CP, Campbell-Hope LJ, Pemberton KD, Dunnett SB (1991) The "staircase test": a measure of independent forelimb reaching and grasping abilities in rats. J Neurosci Methods 36:219-228. CrossRef Medline

Nio J, Fujimoto W, Konno A, Kon Y, Owhashi M, Iwanaga T (2004) Cellular expression of murine $\mathrm{Ym} 1$ and $\mathrm{Ym} 2$, chitinase family proteins, as revealed by in situ hybridization and immunohistochemistry. Histochem Cell Biol 121:473-482. Medline

Pál G, Vincze C, Renner É, Wappler EA, Nagy Z, Lovas G, Dobolyi A (2012) Time course, distribution and cell types of induction of transforming growth factor betas following middle cerebral artery occlusion in the rat brain. PLoS One 7:e46731. CrossRef Medline

Pál G, Lovas G, Dobolyi A (2014) Induction of transforming growth factor beta receptors following focal ischemia in the rat brain. PLoS One 9:e106544. CrossRef Medline

Peters W, Charo IF (2001) Involvement of chemokine receptor 2 and its ligand, monocyte chemoattractant protein-1, in the development of atherosclerosis: lessons from knockout mice. Curr Opin Lipidol 12:175-180. CrossRef Medline

Peters W, Scott HM, Chambers HF, Flynn JL, Charo IF, Ernst JD (2001) Chemokine receptor 2 serves an early and essential role in resistance to Mycobacterium tuberculosis. Proc Natl Acad Sci U S A 98:7958-7963. CrossRef Medline

Prinz M, Priller J (2010) Tickets to the brain: role of CCR2 and CX3CR1 in myeloid cell entry in the CNS. J Neuroimmunol 224:80-84. CrossRef Medline
Raposo C, Graubardt N, Cohen M, Eitan C, London A, Berkutzki T, Schwartz M (2014) CNS repair requires both effector and regulatory T cells with distinct temporal and spatial profiles. J Neurosci 34:10141-10155. CrossRef Medline

Ritzel RM, Patel AR, Grenier JM, Crapser J, Verma R, Jellison ER, McCullough LD (2015) Functional differences between microglia and monocytes after ischemic stroke. J Neuroinflammation 12:106. CrossRef Medline

Rolls A, Shechter R, London A, Segev Y, Jacob-Hirsch J, Amariglio N, Rechavi G, Schwartz M (2008) Two faces of chondroitin sulfate proteoglycan in spinal cord repair: a role in microglia/macrophage activation. PLoS Med 5:e171. CrossRef Medline

Saederup N, Cardona AE, Croft K, Mizutani M, Cotleur AC, Tsou CL, Ransohoff RM, Charo IF (2010) Selective chemokine receptor usage by central nervous system myeloid cells in CCR2-red fluorescent protein knock-in mice. PLoS One 5:e13693. CrossRef Medline

Schaer DJ, Alayash AI, Buehler PW (2007) Gating the radical hemoglobin to macrophages: the anti-inflammatory role of CD163, a scavenger receptor. Antioxid Redox Signal 9:991-999. CrossRef Medline

Sedgwick JD, Schwender S, Imrich H, Dörries R, Butcher GW, ter Meulen V (1991) Isolation and direct characterization of resident microglial cells from the normal and inflamed central nervous system. Proc Natl Acad Sci U S A 88:7438-7442. CrossRef Medline

Shechter R, Schwartz M (2013) Harnessing monocyte-derived macrophages to control central nervous system pathologies: no longer 'if' but 'how'. J Pathol 229:332-346. CrossRef Medline

Shechter R, London A, Varol C, Raposo C, Cusimano M, Yovel G, Rolls A, Mack M, Pluchino S, Martino G, Jung S, Schwartz M (2009) Infiltrating blood-derived macrophages are vital cells playing an anti-inflammatory role in recovery from spinal cord injury in mice. PLoS Med 6:e1000113. CrossRef Medline

Shechter R, Miller O, Yovel G, Rosenzweig N, London A, Ruckh J, Kim KW, Klein E, Kalchenko V, Bendel P, Lira SA, Jung S, Schwartz M (2013) Recruitment of beneficial M2 macrophages to injured spinal cord is orchestrated by remote brain choroid plexus. Immunity 38:555-569. CrossRef Medline

Shichita T, Ito M, Yoshimura A (2014) Post-ischemic inflammation regulates neural damage and protection. Front Cell Neurosci 8:319. CrossRef Medline

Stevens SL, Bao J, Hollis J, Lessov NS, Clark WM, Stenzel-Poore MP (2002) The use of flow cytometry to evaluate temporal changes in inflammatory cells following focal cerebral ischemia in mice. Brain Res 932:110-119. CrossRef Medline

Stoll G, Jander S, Schroeter M (1998) Inflammation and glial responses in ischemic brain lesions. Prog Neurobiol 56:149-171. CrossRef Medline

Tomita M, Fukuuchi Y (1996) Leukocytes, macrophages and secondary brain damage following cerebral ischemia. Acta Neurochir Suppl 66: 32-39. Medline

van Ham TJ, Brady CA, Kalicharan RD, Oosterhof N, Kuipers J, VeenstraAlgra A, Sjollema KA, Peterson RT, Kampinga HH, Giepmans BN (2014) Intravital correlated microscopy reveals differential macrophage and microglial dynamics during resolution of neuroinflammation. Dis Model Mech 7:857-869. CrossRef Medline

Wetzler C, Kämpfer H, Stallmeyer B, Pfeilschifter J, Frank S (2000) Large and sustained induction of chemokines during impaired wound healing in the genetically diabetic mouse: prolonged persistence of neutrophils and macrophages during the late phase of repair. J Invest Dermatol 115: 245-253. CrossRef Medline

Yan YP, Sailor KA, Lang BT, Park SW, Vemuganti R, Dempsey RJ (2007) Monocyte chemoattractant protein-1 plays a critical role in neuroblast migration after focal cerebral ischemia. J Cereb Blood Flow Metab 27: 1213-1224. CrossRef Medline

Yong VW, Rivest S (2009) Taking advantage of the systemic immune system to cure brain diseases. Neuron 64:55-60. CrossRef Medline

Zhou W, Liesz A, Bauer H, Sommer C, Lahrmann B, Valous N, Grabe N, Veltkamp R (2013) Postischemic brain infiltration of leukocyte subpopulations differs among murine permanent and transient focal cerebral ischemia models. Brain Pathol 23:34-44. CrossRef Medline

Zhou X, Spittau B, Krieglstein K (2012) TGFbeta signalling plays an important role in IL4-induced alternative activation of microglia. J Neuroinflammation 9:210. CrossRef Medline 